Article

\title{
An Assessment of Civil Nuclear 'Enabling' and 'Amelioration' Factors for EROI Analysis
}

\author{
Nick King and Aled Jones *(D) \\ Global Sustainability Institute, Anglia Ruskin University, Cambridge CB1 1PT, UK; nick.king@anglia.ac.uk \\ * Correspondence: aled.jones@anglia.ac.uk; Tel.: +44-1223-698931
}

Received: 9 July 2020; Accepted: 8 October 2020; Published: 13 October 2020

\begin{abstract}
Nuclear fission is a primary energy source that may be important to future efforts to reduce greenhouse gas emissions. The energy return on investment (EROI) of any energy source is important because aggregate global EROI must be maintained at a minimum level to support complex global systems. Previous studies considering nuclear EROI have emphasised energy investments linked to 'enabling' factors (upstream activities that enable the operation of nuclear technology such as fuel enrichment), have attracted controversy, and challenges also persist regarding system boundary definition. This study advocates that improved consideration of 'amelioration' factors (downstream activities that remediate nuclear externalities such as decommissioning), is an important task for calculating a realistic nuclear EROI. Components of the 'nuclear system' were analysed and energy investment for five representative 'amelioration' factors calculated. These 'first approximation' calculations made numerous assumptions, exclusions, and simplifications, but accounted for a greater level of detail than had previously been attempted. The amelioration energy costs were found to be approximately 1.5-2 orders of magnitude lower than representative 'enabling' costs. Future refinement of the 'amelioration' factors may indicate that they are of greater significance, and may also have characteristics making them systemically significant, notably in terms of timing in relation to future global EROI declines.
\end{abstract}

Keywords: nuclear fission; greenhouse gas emissions; energy return on investment; energy costs and investments; systemic Impacts

\section{Introduction}

Civil nuclear fission energy has made a contribution to the world primary energy mix for the last 70 years, generating approximately $10 \%$ of the world's electricity output today (equating to approximately $4.5 \%$ of world primary energy supply in 2018), down from a peak of approximately $17 \%$ during the 1980s [1-5]. During this period the success of this energy source has varied in response to changing internal and external economics, major accidents, geopolitics, and other factors. In recent decades, the possibility of a 'renaissance' (i.e., a reversal of the declining contribution described above) has been suggested in some quarters in light of the increasingly urgent global efforts to achieve substantial and meaningful greenhouse gas (GHG) emissions reductions [6-9].

This possibility is based on the ability of this technology to generate steady, reliable, and controllable energy output with much lower carbon emissions than emitted by fossil fuel generation [10], and future expansion could potentially be substantial [5]. However, this remains controversial and open to debate given challenges relating to capital costs, radioactive waste management, and the true GHG emissions of nuclear technology including those emissions associated with the full nuclear lifecycle relative to other 'low carbon' sources, amongst other factors [1,10]. It must also be viewed in the context of the increases in the political, financial, social, and technical feasibility of large-scale renewables generation 
that have occurred in recent decades [11], which lead in turn to further questions over the 'room' for nuclear increases and the 'compatibility' of nuclear with renewables.

Whether or not the use of nuclear energy grows significantly it is likely to remain a significant contributor for the foreseeable future, and a crucial factor to consider for any primary energy source is the 'net energy' that it provides, otherwise described as its 'energy return on investment' (EROI, alternatively described as energy returned on energy invested, ERoEI). This quantifies the ratio of usable, high-quality energy yielded by a source to the energy required to obtain, release, and utilise that energy. Hall et al. [12] list reference EROI values/ranges for electricity generation technologies as: Coal, 27-80:1; oil, 10-65:1; gas, 20-67:1; hydropower, >100:1; wind turbines, 18:1; photovoltaics, 6-12:1; with fossil fuel EROI decreasing over time and renewables EROI increasing over time, although there is a need to take into account storage requirements [13]. More recent estimates for fossil fuels have shown that when considering the point at which energy is used (converted to electricity or use as petrol) then the true EROI has been closer to 6:1 over the past two decades, and is decreasing [14]. These values compare to the nuclear EROI range of 5-2000:1 (discussed in greater detail in Section 1.1.2). However, when comparing EROI figures from different energy sources it is important not to 'compare apples and oranges' [15] and such calculations should include all aspects of energy use from upstream or 'enabling' (point of extraction) to downstream or 'amelioration' (point of use) components.

Long-term global economic growth and stability has historically depended on reliable and continuous supplies of energy with a high EROI value, therefore the aggregate EROI value for all of the energy sources utilised by humans now and in the future has important implications for the ongoing viability and operability of highly complex and interconnected global systems $[16,17]$ and the avoidance of an "energy trap", particularly in the face of projected global-scale perturbations and challenges such as climate change [9,12,18-20].

EROI in its pure interpretation is a quantitative, biophysical measure with inputs and outputs expressed only in physical quantities (units of energy), with no financial/economic/monetary or other similar metrics that may introduce distortions, spurious data, and other fallacies. EROI has therefore proven challenging to robustly quantify for many energy systems due to factors including lack of quantitative data, relevant data being expressed in terms of financial metrics only, and difficulties in the definition of the energy systems in question and their 'boundaries' $[12,15,21]$.

Several researchers have, to date, attempted to define the overall EROI value achieved by nuclear fission technology at the global scale (rather than for any particular technology or location), but the conclusions of these studies have generated debate and controversy [12,22-24]. Nuclear technology and the system it operates within is highly complex, and although the existing body of work has considered the factors that are necessary to build and run nuclear technology (e.g., nuclear fuel enrichment) as well as those that become necessary as a result of nuclear technology (e.g., radioactive waste management), the emphasis and focus of detailed assessment has generally been skewed towards the 'enabling' factors $[6,20]$ and therefore may not capture this complexity adequately.

As such, there is scope to build on this work by approaching the problem with increased focus on the factors that result from the use of nuclear technology, namely decommissioning of shutdown power plants, and management of radioactive wastes. As with the other aspects of the 'nuclear system', these are highly complex and due to the comparative immaturity of this part of the system [1], are relatively novel. Further investigation of these, along with a quantification that provides a first approximation of the total energy requirements, is an important analysis to undertake as it will allow a more balanced assessment of the 'nuclear system' and inform and underpin efforts to improve the understanding of nuclear EROI, as part of future studies.

A more robust and balanced value for the EROI of nuclear technology will in turn make a contribution to the understanding of the implications (i.e., in comparison to alternative global energy pathways) of the proposed future increased penetration of nuclear energy into global energy systems, which may be needed to support the GHG emissions reductions identified as imperative by the international community. 


\subsection{Energy Return on Investment}

EROI is a method [25] for the calculation of net energy, which has been demonstrated to be an effective approach for examining the relative disadvantages and advantages of different energy sources, and as a guide for the assessment of the availability of future energy supplies that is not prone to the failures and distortions of price and market signals. In its simplest terms, EROI is expressed as a dimensionless ratio (assuming the same units are used throughout) calculated as follows:

$\mathrm{EROI}=$ Energy returned to society/Energy required to get that energy.

Although this is a very simple analysis, it can be interpreted in different ways and its application has in some previous instances been controversial [12]. The majority of this controversy has arisen from the definition of the energy system boundaries i.e., the denominator of the above equation. The authors of [25] describe EROI as usually being applied at the point of energy 'capture' (e.g., oil at the wellhead, food at the farm gate), which are instances of a 'small' system boundary with many 'downstream' energy investments necessary for use of energy resources such as processing, transport, etc., being neglected.

There are different types of EROI that utilise a range of system boundaries [12]: (i) Standard EROI $\left(E R O I_{S T}{ }\right.$ - -project/regional/country energy output divided by the sum of direct (on site)/indirect (offsite) energy uses, without consideration of additional factors such as labour or finance; (ii) Point of Use

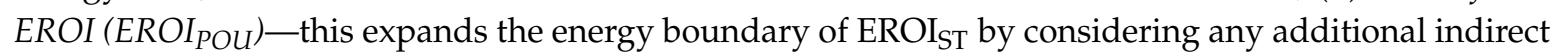
energy investments such as refining and transport; (iii) Extended EROI (EROI $I_{E X T}$ ) — this considers the energy involved in the use of, as well as in the obtaining of, energy sources such that it is minimally useful to society; and (iv) Societal EROI (EROI $I_{S O C}$ ) — this describes a comprehensive EROI value that considers all of a nation's (or equivalent) energy sources and all costs for obtaining these sources.

A similar 'hierarchy' of EROI assessments can be described [26], with numerical levels describing increasing systems boundaries encompassing greater parts of the biophysical energy-economy system: Level 1 (internal energy consumption); Level 2 (external energy consumption); Level 3 (materials consumption); Level 4 (labour consumption); and Level 5 (auxiliary services consumption). Each of these successive levels incorporates additional energy uses and losses (resulting from extraction, processing, etc.) and at the higher levels incorporates more 'abstracted' components of the energy management and use system, such as the labour and financial sectors.

Although the larger, societal-scale EROI analyses incorporate additional factors such as different energy delivery pathways (e.g., electricity vs. hydrocarbon fuels), different scales of analysis (facility vs. region), and the energy conversion efficiencies associated with these, there are challenges also associated with quantification of more localised energy systems $[17,21,25]$. These arise from a high degree of interconnectedness of economic systems, which results in complexities linked to defining boundaries and isolating components. These analyses indicate that EROI can be difficult to reliably define at multiple scales.

It is noted that for any of the forms of EROI described above, it can never be a 'total indicator' as it cannot capture all the relevant information necessary to describe whether an energy source provides a beneficial net output. As such, it is an indicative measure rather than an absolute description.

\subsubsection{The Significance of EROI}

The EROI achieved by global energy systems has significant and far-reaching systemic aspects. A minimum value is required for complex modern societies to function on a continuous basis [25], required largely to build and maintain complexity [27] and to cater for entropic losses. Hall et al. [12] defines this minimum EROI value to be approximately 3.

The key defining feature of the (approximately) 70 years preceding the present has been a very large economic expansion characterised by exponentially rising material and energy throughputs in human systems and increasing perturbation of natural systems during that period (labelled in [28] as the 'Great Acceleration'). This has required reliable access to energy sources with large EROI values 
(approximately $>20$ ), which has largely been achieved through the very large-scale exploitation of readily accessible but finite fossil fuel resources.

However, there is the potential for the primary energy sources available globally to undergo a future reduction in EROI value [9,25]. Such a reduction in overall EROI could jeopardise not only the continuation of the 'Great Acceleration', but also the continued operation of fundamental societal functions (the "energy crunch" described in [29], and potentially the "Seneca effect" described in [30]). The energy system as a component of the networked, interconnected globalised economy is key [16], and the continued provision of high-quality, affordable energy to the global economic system is fundamental to maintaining stability and reducing the risk of cascading failures in its tightly coupled sub-components.

In addition, there is an imperative to achieve substantial GHG emissions reductions in the near future to limit the systemic perturbations and risks that climate change may induce. During any such energy transition the overall EROI value of the global energy system will need to maintain the minimal value that [12] defined, and in reality, a higher value closer to that provided by fossil fuels during the 'Great Acceleration' will likely be required for stability to persist (in part due to the perturbations from 'locked-in' climate changes that may occur during that time). Therefore, the development of a robust understanding of the true EROI value of nuclear technology, including the role of the 'enabling' and 'amelioration' factors, will be crucial for these inter-related systemic risks.

\subsubsection{Nuclear Technology and EROI}

This subsection reviews some of the key studies that have analysed nuclear energy in terms of its net energy and GHG performance (in both absolute and relative terms). This is a subject area that has been covered by a range of studies undertaken over several decades (starting in approximately the 1970s). The following review is restricted to consideration of the most recent studies, which have assessed the net energy performance of nuclear energy using recent data, in the contemporary global setting.

The studies covered in this section encompass a cross-section of approaches and viewpoints, but which consistently focus on biophysical analyses i.e., the energy balance, EROI, and GHG emissions of nuclear technology. Studies considering the financial aspects of nuclear technology are not considered in this analysis, however it is acknowledged here that nuclear power has generally not provided financial returns commensurate with that of fossil fuel energy sources [31], which is indirectly significant for consideration of EROI.

Weissbach et al. [23] calculated EROI/energy intensity/payback times for different energy sources and concluded that the nuclear EROI value (using pressurised water reactor and centrifuge-based fuel enrichment technology as representative) was in the range 75-105:1 (rising to 115:1 if laser-based enrichment is applied). This paper also analyses the EROI performance of other energy sources (including fossil fuels, renewables, and hydroelectric energy), and the output of the analysis places nuclear energy very favourably in the hierarchy of EROI performance.

It is noted that although this paper [23] is referenced by several sources (e.g., [32]) it has attracted some controversy. Comments challenging the methodology applied were made in a short paper, which the study authors then responded to in 2014, which in turn generated further comments in the form of a rebuttal from the original commentators [24,33].

A further study [22] considered lifecycle energy balances and GHG emissions linked to different components of the nuclear fuel cycle within the context of the Australian national energy system. The study provides detailed descriptions of the factors with a significant bearing on lifecycle and GHG emission performance (e.g., ore grades, reactor technologies, the carbon intensity of the economy nuclear technology is nested within). This study does not explicitly calculate an overall EROI value, but does provide high-level description and quantification of the various major 'subsystems' of the 'nuclear system' in the context of the Australian national energy system, which are applicable to EROI calculation and are applied as a basis to the analysis in this paper (see following subsection). 
Other analysis [10] incorporates the energy expenditures linked to decommissioning (power plant dismantling) and the management of radioactive wastes, including geological disposal. These are characterised as amongst the most challenging components to analyse, due to the lack of available data on the associated energy requirements. The lifecycle assessments considered in this study provide a wide range of overall (indirect) GHG emissions per-unit energy generated by nuclear due to ranges of input data, assumption, and estimations, which would make nuclear comparable with some renewables in terms of GHG emissions to significantly greater (though still much lower than for fossil fuels).

Within a systematic appraisal of the claim that nuclear power is a low-carbon energy source [34], various factors are analysed, including the contribution of nuclear to GHG mitigation currently and in the future, the rate of the addition of new nuclear capacity, prospects for advanced nuclear technology, uranium resources, $\mathrm{CO}_{2}$, and other GHG emissions, and performance relative to renewable energy sources. This study broadly concludes that the scope for large-scale future expansion of nuclear power is likely to be constrained by several factors, and that as a technology it generates significant GHG emissions and does not generally compare favourably with renewable energy technologies. This study also introduces two key, interrelated concepts of particular relevance to decommissioning and waste management, which are Latent Entropy and Energy Debt. Latent Entropy broadly refers to the net increase in entropy to the (global) environment that would result if radioactive waste and contaminants were to be improperly controlled, and Energy Debt to the energy that will need to be expended in future to ensure that Latent Entropy is appropriately controlled.

Upfront capital costs, uranium grade ores (i.e., 'enabling' factors), and 'environmental costs' (i.e., decommissioning and waste management activities required to limit environmental damage) are the three major drivers for nuclear EROI [35]. As a result of these energy requirements, the EROI performance in nuclear is lower than several other energy sources [35,36], notably conventional fossil fuels, wind, and hydropower, and broadly commensurate with photovoltaics.

However, the proposed Generation IV nuclear reactor concept (the dual fluid reactor, DFR) offers the possibility of achieving very high EROI values [37]. The proposed DFR is a liquid metal-cooled fast reactor concept that offers the unique feature of also using liquid, molten salt-based fuel, which offers high-performance neutron economy and fuel burnup capabilities, and material features that would allow high power density and heat output. This concept offers the possibility of simplified fuel reprocessing and a novel combination of secondary (i.e., other than power production) applications such as fuel breeding, waste 'burnup', and provision of industrial heat. Based on the unique combination of attributes that this concept incorporates, an EROI value of up to 2000:1 could be achievable [37]. This is orders of magnitude higher than the EROI ranges indicated by other literature for all other energy sources. The veracity of these claims is open to interpretation given that, for example, the study does not discuss factors such as technical readiness level (i.e., an analysis of how close to operational status the concept is, which would indicate the magnitude of energy investment required for the technology to reach that status), and does not acknowledge that most of the novel systems and materials have not been tested even at laboratory scale. It also cites an EROI value for existing nuclear power systems that is derived from [23], which as described above remains controversial [24,33].

Overall, the review of literature relating to the EROI (and GHG emission) performance of nuclear technology indicates that this metric is far from settled and agreed. Table 1 summarises published nuclear EROI ranges/values, which shows the large range of values that have been calculated. It is noted that there are two clear groupings; one group [12,35] stating values that approximate to 10:1, and a second group [23,37] approximating to $>100: 1$ (it is noted that the second group is linked to more controversial studies). 
Table 1. Comparison of published nuclear energy return on investment (EROI) ranges/values.

\begin{tabular}{|c|c|c|}
\hline EROI Value & Data Sources and Discussion & Discussion of 'Enabling' and 'Amelioration' Factors \\
\hline $5-8: 1$ & $\begin{array}{l}\text { For nuclear, a range of }<1-60: 1 \text { is presented [35] from recent/contemporary } \\
\text { studies, but the authors conclude that many the underpinning assumptions of } \\
\text { these studies are alternately too pessimistic or optimistic. The older nuclear } \\
\text { EROI range of approximately 5-8:1 is described as being the most reliable. } \\
\text { The authors note that the factors underpinning these ranges of figures include } \\
\text { whether electricity is corrected for quality, and energy system boundaries and } \\
\text { technologies. They also note that there is dearth of empirical information to } \\
\text { support analysis of differences in EROI, but calculation of EROI in response to } \\
\text { factors such as the long operational period of nuclear power plants and } \\
\text { depleting uranium reserves would be beneficial. }\end{array}$ & $\begin{array}{l}\text { This study discusses several aspects of these factors at the conceptual } \\
\text { level. For the 'enabling' factors, capital costs, costs linked to obtaining } \\
\text { uranium (i.e., whether obtained from already-processed uranium taken } \\
\text { from dismantled weapons or from depleting geological sources) and the } \\
\text { type of nuclear technology are noted as significant. For the 'amelioration' } \\
\text { factors, 'environmental costs' are cited. The study does not provide } \\
\text { detailed explanations for these 'environmental costs', but these are } \\
\text { assumed to encompass the energy expenditure linked to the remediation } \\
\text { of environmental pollution arising from nuclear operations, } \\
\text { and management of nuclear waste (i.e., the subject matter of this study). }\end{array}$ \\
\hline 14:1 & $\begin{array}{l}\text { A mean EROI value calculated through a meta-analysis (using } 33 \text { different } \\
\text { EROI figures derived from } 15 \text { separate studies) is presented in [12,38]. The } \\
\text { authors note that the figures contributing to this calculation are in some cases } \\
\text { dated. Appraisal of the references [38] indicates that a number of the } \\
\text { contributing studies are older and discuss EROI more generally i.e., are not } \\
\text { studies devoted solely to nuclear EROI. The key underpinning source for [35], } \\
\text { was the source of a key method for EROI calculation applied to assess the } \\
\text { societal significance of EROI in this study [38]. The relatively high averaged } \\
\text { EROI value for nuclear may be in part due to not having corrected for the high } \\
\text { quality of the output from nuclear power (electricity), but whether to make } \\
\text { this correction as part of the methodological approach for nuclear EROI was } \\
\text { unresolved at the time of writing [12]. }\end{array}$ & $\begin{array}{l}\text { Two of the 'enabling' factors at very high level, in the context of the older } \\
\text { studies cited, are not fully reflective of contemporary nuclear } \\
\text { technologies and/or uranium ore grades [12], although specific } \\
\text { discussion or analysis of either of the factors are not always } \\
\text { undertaken [38]. }\end{array}$ \\
\hline 75-115:1 & $\begin{array}{l}\text { Another study [23] analyses EROI for several different energy sources, } \\
\text { including a range of EROI values for existing light-water nuclear technology. } \\
\text { The data points applied in this analysis (which are in raw energetic terms, } \\
\text { with a proportion supplied by electrical power indicated for several of the } \\
\text { metrics) are for a reference nuclear plant in the US. The data sources for this } \\
\text { are of varying age and include a limited number of common references with } \\
{[12,35,38] \text {. The range of overall EROI figures is attributable to different energy }} \\
\text { values linked to the application of different uranium enrichment technologies; } \\
\text { the lower EROI value ( } 75: 1 \text { ) is for the partial use of centrifuge technology, the } \\
\text { middle figure (105:1) is for the use of } 100 \% \text { centrifuge technology, and the } \\
\text { highest figure (115:1) is for the application of laser-based enrichment } \\
\text { techniques. The decommissioning and other figures used in calculating these } \\
\text { EROI values are singular and fixed in each of these instances. }\end{array}$ & $\begin{array}{l}\text { This study provides a descriptive and quantitative breakdown of both } \\
\text { factors. For the 'enabling' factors, construction, maintenance and fuel } \\
\text { energy demand (encompassing uranium extraction and enrichment) are } \\
\text { accounted for. The 'amelioration' factors are accounted for in a single } \\
\text { 'decommissioning' figure, but the components contributing to the energy } \\
\text { expenditure for this figure are not provided in the study. }\end{array}$ \\
\hline
\end{tabular}


Table 1. Cont

Based on the capabilities purported for a novel, conceptual Generation IV

nuclear reactor technology (the DFR), an EROI of approximately 2000:1 could be achieved. The study also states a theoretical maximum EROI for nuclear of 10,000:1, calculated based on 3 ppm U-content ores, and construction,

maintenance, decommissioning and waste management energy costs being neglected. The discussion of EROI in this paper focuses primarily on two aspects that are stated as making substantial contributions to the very high EROI figure; the lower energy requirements for fuel processing (the efficiency of the system combined with the reactor's neutronics and mode of operation lower this energy requirement) and construction (the reactor itself is smaller and simpler than extant light water designs). The arguments presented either fail to account for several factors necessary for robust EROI calculation, or do not provide the level of detail that would be expected to support a bold claim regarding EROI. This fact, combined with the lack of acknowledgement of the unproven and untested nature of much of what is being proposed, mean that

the EROI figure presented in this study is not as robust as other studies.

This study provides descriptive breakdowns for both factors, and quantitative breakdowns for the 'enabling' factors. For the 'enabling' factors construction, fuel and maintenance are noted as the most significant components. A detailed quantitative breakdown of the energetic requirements for materials used the DFR (for the reactor structure and various components, fuel and coolant) along with energetic requirements for maintenance of the reactor are used to calculate the cited EROI value. Underpinning references for the cited energetic values are not provided. For the 'amelioration' factors, decommissioning is noted as a contributor to EROI calculations, but no breakdown (qualitative or quantitative) is provided for this in the study. 
The literature review therefore indicates that further work is required to refine the EROI value of nuclear. Therefore, further investigation of the nuclear system/nuclear fuel cycle with an emphasis on decommissioning, waste management, and geological disposal is likely to be an important and valuable task in the calculation and underpinning of a robust, 'modern' nuclear EROI figure.

Table 1 is a breakdown of existing studies that have either directly calculated nuclear EROI values or summarise discussions and EROI calculations undertaken in preceding studies. This describes the data sources and discussions presented in these studies, and also provides a breakdown of which part of the nuclear system is emphasised. In terms of energy costs and investments, the nuclear system can be considered to comprise two parts, which are factors that underpin and enable the operation of nuclear technology (herein labelled as the 'enabling' factors) and the 'externalities' that result from the use of nuclear technology, and which must be addressed through appropriate means (herein are labelled as the 'amelioration' factors) It is noted that this term has been used throughout this study, as it alludes to 'improvement'. As noted below, the 'amelioration' factors are essential to the operation of nuclear technology; its use generates contaminants and other hazards that affect the environment and ecosystems (i.e., Latent Entropy [34]), and measures must consequently be taken to improve these systems. It is this requirement to respond to the effects of the operation of nuclear technology that differentiates the 'amelioration' factors from the 'enabling' factors.

The studies outlined (directly or indirectly) in Table 1 describe the 'amelioration' factors either in only conceptual and high-level terms, or where these factors are covered in more detail or are included in calculations they are combined into a singular 'decommissioning' term with scant underpinning detail. None of the studies have attempted to undertake a detailed description of the various components comprising the 'amelioration' factors or their nuances and complexities at different scales, nor to undertake systemic, underpinning calculation of the energetic costs of these components. As such, there is unfulfilled scope in the literature to improve understanding of nuclear EROI by describing the different aspects of the 'amelioration' factors in detail, and to undertake a 'first approximation' of their energetic costs at the large scale.

\subsection{Description of the 'Nuclear System'}

A breakdown of the 'nuclear system' by energetic input [22], which robustly captures the totality of the different 'subsystems', is as follows: (i) Uranium mining; (ii) uranium milling; (iii) conversion to uranium hexafluoride; (iv) enrichment; (v) fuel fabrication; (vi) reactor construction; (vii) reactor operation; (viii) decommissioning; (ix) fuel reprocessing; (x) nuclear waste storage; (xi) nuclear waste disposal; and (xii) transport.

This list can be considered as a list of interdependent and interacting 'subsystems' that in combination comprise the overall 'nuclear system'. The grouping of ' $i$-vii' are the 'enabling' factors, and the grouping of 'vii-xi' are the 'amelioration' factors. Note that 'ix' is not considered to meet this definition as it has only been implemented by some nations during different time periods, and 'xii' is considered to be a separate factor applicable to both the 'enabling' and 'amelioration' factors (and is therefore considered further).

The following subsection links these 'enabling' and 'amelioration' 'subsystems' as fundamental biophysical features and energy investments for EROI analysis.

\subsection{Balanced Re-Assessment of the Nuclear System}

A key feature noted as being common to previous studies [22,23] (and which therefore is broadly reflective of the conclusions and viewpoints of these studies) is that the 'enabling' factors (and in particular fuel enrichment) together comprise the dominant energy investments for the nuclear system. While others $[23,34,35]$ provide a description of the key role of the 'amelioration' factors (e.g., under the description of 'energy debt'), and quantification is undertaken [16,17]. the consideration they are given lacks certain specific detail and breakdown of their features, and how energy is used in discharging them. This study aims to build on the existing body of work on nuclear EROI by advocating and 
underpinning the viewpoint that a comprehensive, holistic, and balanced conceptual description of the nuclear energy system should be undertaken to quantify EROI. Increased attention and focus on the energetic inputs associated with the 'amelioration' factors (in parallel and addition to the 'enabling' factors) is a necessary task to ensure that EROI calculations are as reflective of reality as possible.

These 'amelioration' factors are an inevitable result of the use of nuclear technology, and although not strictly needed to make energy usable in biophysical terms (nuclear technology could continue to be physically operated even if redundant facilities and radioactive wastes were not appropriately managed), in the 'real world', there are legal, environmental, economic, and moral pre-requisites for nuclear power to continue to operate, so the 'amelioration' factors are therefore synonymous with, and are considered to be, biophysical necessities. Therefore, the effective management of these factors is imperative to the continued use of the technology in all countries and jurisdictions with nuclear programmes.

The lack of balance between the consideration of the 'enabling' and 'amelioration' factors should be addressed in order to be fully reflective of the 'nuclear system', and the first stage of that is to fully characterise the 'amelioration' factors. These are inherently complex, long-term, novel, and in some areas, energetically demanding [1]. These factors have however yet to be given consideration with the depth or granularity commensurate to their potential real-world importance in existing work [6], therefore a framework for their full inclusion and assessment will be necessary if a truly robust and realistic analysis of nuclear EROI is to be attempted.

Any comprehensive, balanced and realistic assessment of the 'nuclear system' will need to give significant credence to the 'enabling' factors, in line with previous studies, in parallel to the 'amelioration' factors. This will also provide the opportunity to draw similarities, contrasts, and proportionalities between these factors. Both are characterised by complexity and geographical distribution, but the 'enabling' factors have been undertaken continuously since the use of nuclear technology first became widespread (circa 70 years ago [1]), and as a result are generally more integrated into existing global infrastructure and supply lines, and have significant existing capital investment and sunk costs (for the construction of major infrastructure such as mines and fuel enrichment facilities).

By contrast, the 'amelioration' factors can generally be described as more novel, and as being at development/early deployment stage, so will require future capital investment and will involve long lead-in and implementation times. There are 181 closed nuclear reactors worldwide [1] with approximately another 200 to enter the decommissioning phase by 2030, and decommissioning is seen as being at an early stage worldwide and will likely pose major challenges in terms of long-term planning, execution, and financing due to its technical complexity. Therefore, it is likely to attract increasing public attention in future. However, some argue decommissioning programmes are likely to become more routine with increasing experience and industrial-scale operation [39].

From a biophysical standpoint, the 'enabling' factors can be generally characterised as requiring energy input to manufacture precision items and materials, and to undertake large-scale (but generally routine) civil engineering. By contrast, the 'amelioration' factors generally require energy expenditure to remediate spatially large systems in a high-entropy state (dismantling of hazardous structures, remediation of diffuse contamination, separation of well-mixed waste products), as well as to manufacture precision items and materials, and to undertake very large, complex, and novel civil engineering (notably, construction of geological disposal facilities). The Latent Entropy and Energy Debt concepts described by [34] capture the particular biophysical challenges linked to the 'amelioration' factors.

This study will provide a novel addition to the collective work on nuclear EROI by describing and quantifying detailed aspects of the 'amelioration' factors. Several of the studies described in this paper (notably [10,34]) provide descriptions of decommissioning and waste management (including geological disposal) activities, but these are high level and do not attempt to describe details (e.g., materials usage, strategies with reference to real decommissioning programmes) of these activities, nor link these activities directly to 'real' energy expenditures. This quantification will allow 
an approximation of the energy expenditure of the 'amelioration' factors, to inform future EROI calculations (see Section 2.1 for further detail).

Assessment of the 'amelioration' factors will be complex, and as noted by [10], any analysis attempted will have a dearth of existing underpinning biophysical data. As a guide to this, the following subsection provides descriptions and examples of international nuclear decommissioning and geological disposal programmes, in order to illustrate their scope, magnitude, and complexity.

\subsection{Description of National Projects Incorporating the 'Amelioration' Factors}

Tables 2-9 provide details of example nuclear decommissioning and geological disposal programmes for a number of selected countries, along with one aspect of the Chernobyl disaster remediation project and overviews of operational geological disposal facilities. It is noted that there are numerous major decommissioning programmes underway in multiple countries around the world (in Europe, North America, Asia, and elsewhere), but a representative cross section of six national nuclear decommissioning/geological disposal programmes were selected on the basis that these programmes are well-developed and technically advanced, are highly public-facing, and therefore have details published in the public domain.

In addition to these national programmes, information is presented for the Chernobyl remediation project, and the waste isolation pilot plant (WIPP), and the Bátaapáti radioactive waste repository. Combined, these provide illustrative descriptions of the magnitude of the 'amelioration' factors at the global scale.

Financial data are provided against each of these national projects. This study is explicitly focused on biophysical metrics, so this financial data are provided for general underpinning, i.e., to convey the scale of these projects, given that financial expenditure is a proxy for energy use. All financial quantities have been converted to US Dollars (using the August 2020 exchange rate) to allow comparison of the scales of the different national projects.

\subsubsection{United Kingdom}

The UK was an early nuclear power (Table 2) that undertook pioneering R\&D for civil and military purposes and operated 15 reactors in 2018 (generating 18\% of its electricity) [1]. As a result, the UK has a large, complex nuclear legacy, the management of which is led by the Nuclear Decommissioning Authority (a non-departmental public body) on behalf of central government [40].

Table 2. Nuclear 'amelioration' projects in the UK.

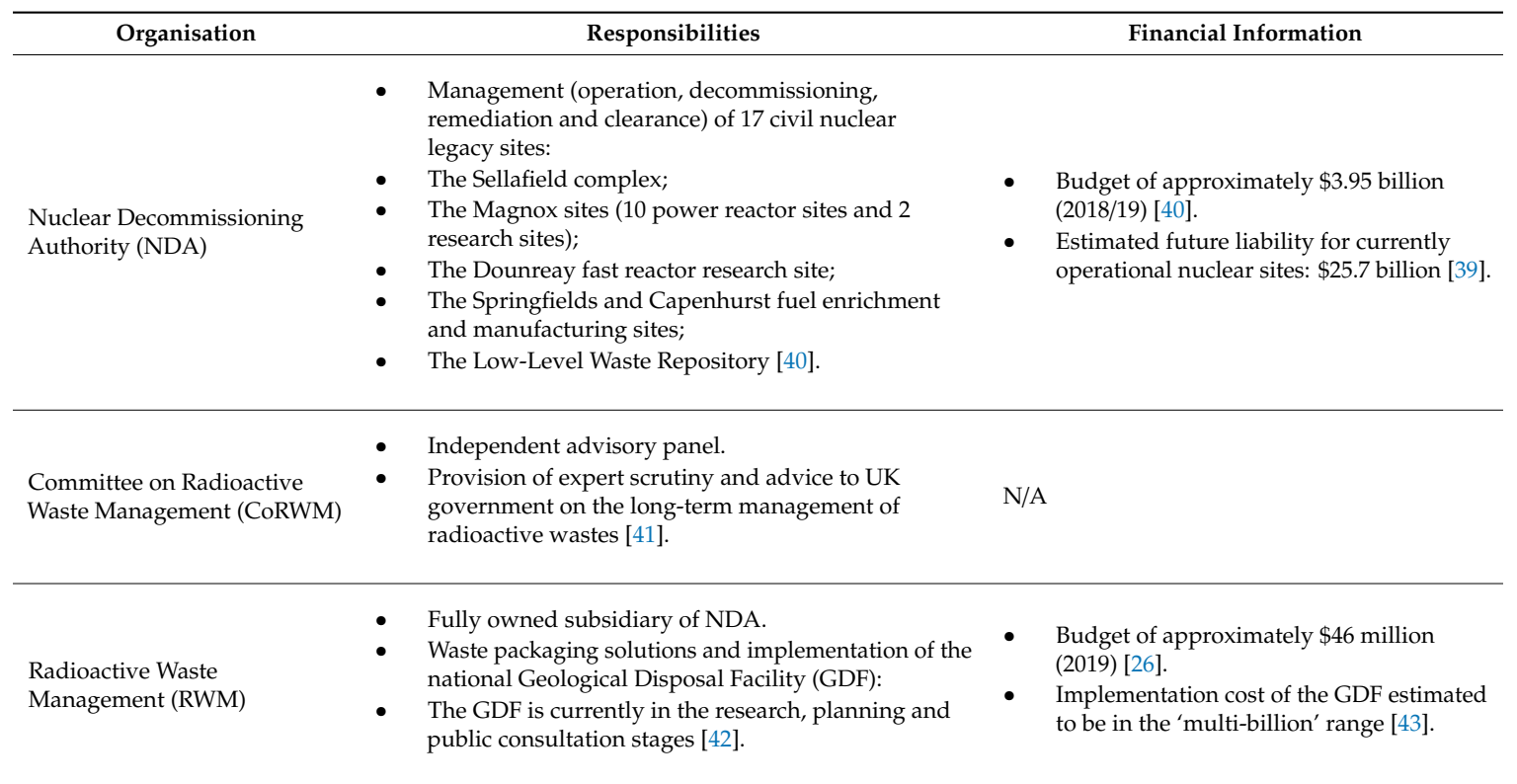




\subsubsection{France}

France embarked on a large scale civil nuclear power programme (Table 3) and as a result operated 58 reactors in 2018 (generating 72\% of its electricity), which along with a closed nuclear fuel cycle and military applications of nuclear technology, has resulted in a large, complex nuclear legacy [1]. This is managed through a public industrial and commercial entity [44].

Table 3. Nuclear 'amelioration' projects in France.

\begin{tabular}{|c|c|c|}
\hline Organisation & Responsibilities & Financial Information \\
\hline $\begin{array}{l}\text { L'Agence nationale pour la gestion } \\
\text { des déchets radioactifs (ANDRA) }\end{array}$ & $\begin{array}{l}\text { Management of all types of radioactive } \\
\text { waste from nuclear activities } \\
\text { throughout France: } \\
\text { Not directly involved in the reactor } \\
\text { decommissioning or fuel reprocessing. } \\
\text { Implementation of the Cigéo geological } \\
\text { disposal project in north-eastern France: } \\
\text { Cigéo is at an advanced stage of R\&D and } \\
\text { construction is estimated to commence } \\
\text { within approximately } 10 \text { years [44]. }\end{array}$ & $\begin{array}{l}\text { Budget of approximately } \\
\$ 270 \text { million (2016) [44]. }\end{array}$ \\
\hline
\end{tabular}

\subsubsection{Switzerland}

Switzerland operated five reactors in 2018 (generating 38\% of its electricity) [1]. The country's nuclear legacy is managed through a co-operative made up of the Swiss federal government (Table 4) and commercial nuclear operators [45]. Nationale Genossenschaft für die Lagerung radioaktiver Abfälle (NAGRA) developed the mild steel canister engineered barrier concept for 'lower strength sedimentary rock' host geology [46].

Table 4. Nuclear 'amelioration' projects in Switzerland.

\begin{tabular}{|c|c|c|}
\hline Organisation & Responsibilities & Financial Information \\
\hline $\begin{array}{l}\text { Nationale Genossenschaft für } \\
\text { die Lagerung radioaktiver } \\
\text { Abfälle (NAGRA) }\end{array}$ & $\begin{array}{l}\text { Management of nuclear decommissioning } \\
\text { throughout Switzerland. } \\
\text { Implementation of national geological } \\
\text { disposal project: } \\
\text { - Management of underground R\&D facilities } \\
\text { and leadership in research [47]. } \\
\text { Investigation of potential sites for geological } \\
\text { disposal [45]. }\end{array}$ & $\begin{array}{l}\text { Decommissioning/ } \\
\text { disposal funds of approximately } \\
\$ 2.6 / 5.6 \text { billion, respectively } \\
(2018) \text { [45]. }\end{array}$ \\
\hline
\end{tabular}

\subsubsection{Sweden}

Sweden operated eight reactors in 2018 (generating 40\% of its electricity) [1]. The country's nuclear legacy (Table 5) is managed through a company comprising Swedish nuclear power operators [48]. Svensk Kärnbränslehantering AB (SKB) developed the KBS-3 engineered barrier concept (" ... multi-barrier system in the bedrock at 400-700 $\mathrm{m}$ depth below the ground surface, with the spent fuel encapsulated in copper canisters with a cast iron insert, which are surrounded by a bentonite buffer") for use in 'higher strength rock' host geology [46,49]. 
Table 5. Nuclear 'amelioration' projects in Sweden.

\begin{tabular}{|c|c|c|}
\hline Organisation & Responsibilities & Financial Information \\
\hline $\begin{array}{l}\text { Svensk Kärnbränslehantering } \\
\mathrm{AB}(\mathrm{SKB})\end{array}$ & $\begin{array}{l}\text { - } \quad \text { Management of nuclear decommissioning } \\
\text { throughout Sweden. } \\
\text { - Implementation of the Forsmark geological } \\
\text { disposal project in eastern Sweden: } \\
\text { - } \quad \text { Management of underground R\&D facilities. } \\
\text { Forsmark is at an advanced stage of R\&D } \\
\text { and construction is estimated to commence } \\
\text { within approximately } 10 \text { years [48]. }\end{array}$ & $\begin{array}{l}\text { 'Total reference costs' (licence } \\
\text { holders' future costs) estimated } \\
\text { at } \$ 10.7 \text { billion [48]. }\end{array}$ \\
\hline
\end{tabular}

\subsubsection{Finland}

Finland operated four reactors in 2018 (generating 32\% of its electricity) [1]. The national management of radioactive waste (Table 6) is led by a company comprising two Finnish nuclear power operators [50].

Table 6. Nuclear 'amelioration' projects in Finland.

\begin{tabular}{lll}
\hline Organisation & \multicolumn{1}{c}{ Responsibilities } & Financial Information \\
\hline & \multicolumn{1}{c}{$\begin{array}{l}\text { Implementation of the Onkalo geological disposal project in } \\
\text { western Finland: }\end{array}$} \\
Panagement of underground R\&D facilities. & $\begin{array}{l}\text { Mannover' of approximately } \\
\text { Construction of surface waste processing facilities and the }\end{array}$ & \$91 million (2018) [50]. \\
& $\begin{array}{l}\text { This is the most advanced civil geological disposal programme in } \\
\text { the world, and waste emplacement operations are planned to } \\
\text { commence within approximately five years [50]. }\end{array}$ & \\
\hline
\end{tabular}

\subsubsection{Canada}

Canada operated 18 reactors in 2018 (generating 15\% of its electricity) [1]. The national management of radioactive waste (Table 7) is led an organisation comprising Canadian nuclear power operators [51].

Table 7. Nuclear 'amelioration' projects in Canada.

\begin{tabular}{|c|c|c|}
\hline Organisation & Responsibilities & Financial Information \\
\hline $\begin{array}{l}\text { Nuclear Waste Management } \\
\text { Organisation (NWMO) }\end{array}$ & $\begin{array}{l}\text { Implementation of national geological } \\
\text { disposal project: } \\
\text { - } \quad \text { Investigation of potential sites for } \\
\text { geological disposal. } \\
\text { - A preferred site is estimated to be identified } \\
\text { with approximately five years [51]. }\end{array}$ & $\begin{array}{l}\text { - } \quad \text { Budget of approximately } \\
\$ 87.2 \text { million (2018). } \\
\text { Total cost of implementation } \\
\text { of geological disposal } \\
\text { estimated at approximately } \\
\$ 17.5 \text { billion [51]. }\end{array}$ \\
\hline
\end{tabular}

\subsubsection{Ukraine (Chernobyl)}

The severe radioactive contamination of the destroyed reactor structure (Table 8), its immediate surrounds, and the nearby environment resulting from the 1986 Chernobyl disaster represents the 'long-tail' of nuclear 'amelioration' (i.e., a rare event, but with severe, long-term consequences). The strategic efforts to manage and remediate the site are internationally led and funded [52]. 
Table 8. Nuclear 'amelioration' projects associated with the Chernobyl site.

\begin{tabular}{|c|c|c|}
\hline Organisation & Responsibilities & Financial Information \\
\hline $\begin{array}{l}\text { Shelter Implementation } \\
\text { Plan/New Safe } \\
\text { Confinement Project }\end{array}$ & $\begin{array}{l}\text { - The most prominent element of this project is the } \\
\text { New Safe Confinement. } \\
\text { This comprises construction of a very large new } \\
\text { shelter structure over the damaged No. } 4 \text { reactor, } \\
\text { to secure it, allow its dismantling, and contain any } \\
\text { further releases of radioactivity [52]. }\end{array}$ & $\begin{array}{l}\text { Total budget of approximately } \\
\$ 2.5 \text { billion [52]. }\end{array}$ \\
\hline
\end{tabular}

\subsubsection{Operational Geological Disposal Facilities}

Table 9 provides an overview of the two geological disposal facilities (Table 9) that have been brought to fully operational status (i.e., which are actively accepting waste packages) internationally; WIPP in the USA, and the Bátaapáti radioactive waste repository in Hungary.

Table 9. Nuclear 'amelioration'—geological disposal.

\begin{tabular}{lll}
\hline \multicolumn{1}{c}{ Organisation } & \multicolumn{1}{c}{ Responsibilities } & Financial Information \\
\hline & WIPP has been accepting waste packages since 1999 & \\
US Department of & $\begin{array}{l}\text { All of the waste packages contain materials contaminated } \\
\text { with anthropogenic transuranics (Intermediate Level }\end{array}$ & Total FY 2019 budget of \\
$\begin{array}{l}\text { Energy/Nuclear Waste } \\
\text { Partnership }\end{array}$ & $\begin{array}{l}\text { Waste) originating from defence projects. } \\
\text { Packages are emplaced in chambers approximately } 600 \mathrm{~m}\end{array}$ & approximately \$397 million [53]. \\
& below the surface within evaporite rock [53] & Total construction cost of \$310 \\
& The Bátaapáti radioactive waste repository has been & million [55] \\
& accepting waste packages since 2012 & \\
PURAM & Level Waste originating from the Paks nuclear power plant & \\
& Packages are placed in chambers within granitic rock [54] & \\
\hline
\end{tabular}

\section{Materials and Methods}

\subsection{Background}

The basis for the quantification of the 'amelioration' factors is to use the categories provided by [22], and further break these down to a greater level of descriptive detail. Table 10 provides this breakdown, with reference to the high-level nuclear decommissioning strategy being implemented in the UK [40,42] (assumed to be broadly representative of international strategies). 
Table 10. Breakdown and factors to be included (listed as ' $Y$ ' in selected) in the 'amelioration' factors and an assessment of whether they are potentially significant in the EROI calculation (see Appendix A).

\begin{tabular}{llc}
\hline \multicolumn{1}{c}{ Decommissioning } & Potential Significance of Energy Investment & Selected Factors \\
\hline - Reactor defueling & Likely not a significant energy investment \\
\hline $\begin{array}{l}\text { Remediation/dismantling/demolition of redundant } \\
\text { structures/infrastructure }\end{array}$ & Likely to be a significant energy investment \\
\hline - $\begin{array}{l}\text { Environmental remediation (land/water/ecosystems) } \\
\text { Enabling civil engineering for all of these factors }\end{array}$ & Likely to be a significant energy investment \\
\hline $\begin{array}{l}\text { Manufacture of 'passivated' (inert and immobile) waste } \\
\text { packages; cementation and vitrification of waste materials }\end{array}$ & Likely to be a significant energy investment \\
\hline
\end{tabular}

- $\quad$ Long-term storage of waste packages in purpose-built facilities operated under controlled conditions

Likely to be a significant energy investment

n

\begin{tabular}{lll}
\hline & Nuclear Waste Disposal \\
\hline - $\quad$ Construction of geological disposal ${ }^{1}$ facilities & Likely to be a significant energy investment \\
\hline $\begin{array}{l}\text { Materials for engineered barriers (containment); bentonite, } \\
\text { cement and metallic containers }\end{array}$ & Likely to be a significant energy investment \\
\hline Long term operation of facilities & Likely to be a significant energy investment
\end{tabular}

Transport

- International transport of bulk materials for engineered barriers

Likely to be a significant energy investment

Y

- Intra-national transport of waste packages to geological disposal facilities

Likely not a significant energy investment

$\mathrm{n}$

\section{OTHER}

- Human capital required to support 'amelioration' factors

Likely not a significant energy investment $\mathrm{n}$

${ }^{1}$ Ref. [41] notes that geological disposal is the technical approach for management of radioactive wastes that offers the optimal mix of technical and economic feasibility along with scientific underpinning for providing long-term passive safety for humans and ecosystems, and therefore recommended this approach to the UK government. Other nations have undertaken equivalent exercises and reached the same conclusion i.e., that the evidence for the ability of geological disposal to provide effective, passive containment for hazards arising from radioactive wastes over extended timescales, based on engineered barriers and stable geological formations, is compelling. This is particularly the case in comparison with indefinite surface storage (which requires active monitoring and would eventually require financial/energy input to maintain the integrity of the wastes, and makes an assumption about the long-term stability of complex societies), and the technical and economic non-feasibility of alternative proposals (e.g., disposal in subduction zones or by launching into space). It is also noted that geological disposal has been the subject of scientific and policy studies internationally for several decades yet has been brought to operational status in only a very limited number of cases to date (see Table 9). Nonetheless, several of the programmes described in Section 1.4 are highly advanced, and [50] describes the anticipated first emplacement of waste packages in the Onkalo repository that is being developed by Posiva Oy in Finland within the 2020s. The WIPP and Bátaapáti radioactive waste repositories, along with successful emplacement of civil waste in Onkalo, will demonstrate that there is likely to be no fundamental impediment or flaw in the overall concept, however successful implementation in other nations will be subject to local challenges and complexities (e.g., system of government, public acceptance, funding etc.), so success in one location does not guarantee that it is universally implementable. Furthermore, the planning and construction of these facilities is only part of the challenge; it will only be with the accrual of safe operational experience, and demonstration of their ability to mitigate hazards on longer timescales, that they will be demonstrably successful. 
The figure(s) calculated will represent a 'grand total', whole-system value for the 'amelioration' factors for all of the nuclear facilities in all countries with nuclear programmes. It will consider the total energy cost from the perspective of a theoretical point in the future when all nuclear facilities have been fully decommissioned, and all waste managed.

The quantification that is attempted here is caveated as being a 'first approximation' of the problem, given its novel nature and the simplifications and interpretations applied. These are necessary to produce a shortlist of easily definable factors on which the calculation will focus, for which numerous assumptions, exclusions, and analogies will be necessarily made in order to undertake a practical and comprehensible set of calculations. Significant allowances will also be necessary for the large uncertainties associated with these calculations, and the smoothing of heterogeneous factors, e.g., international variation in the application of nuclear technology.

The data and references used in these calculations will be taken from the national nuclear 'amelioration' programmes (described in Sections 1.4.1-1.4.7) where possible and available, and robust, representative general references where not, or where data from outside the nuclear system are required. The intent of this first approximation is to illustrate the complexity of the different aspects of the 'amelioration' factors, indicate the types of data and other considerations that must be factored into these calculations, and to generate outputs that will convey the magnitude of the 'amelioration' factors relative to the 'enabling' factors.

The output of these calculations will form the basis and underpinning for future work that will refine and improve the calculation through the use of improved data, more sophisticated calculations, and inclusion of a wider range of energy-consuming factors. The intended endpoint of this effort is a range of highly refined and underpinned figures for both the 'enabling' and 'amelioration' factors, which combined will comprise the 'denominator' of future EROI calculations for the use of nuclear technology at the global scale.

\subsection{Calculation Structure}

Each of the factors listed in Table 10 will need to be assessed in terms of their relative overall contribution to the 'amelioration' factors, and the feasibility of quantifying them. This will be carried out according to the methodology outlined in Table 11. The methodology was applied to each of the factors listed as selected in Table 10, and the results are presented in Appendix A (Tables A1-A12).

\subsection{Exclusions from the Calculation}

As noted in Section 2.2 and in Appendix A, the calculations undertaken as part of this study considered a simplified model of the 'amelioration' part of the nuclear system, with significant exclusions. These factors (captured under 'To be quantified as part of future work' in Appendix A) were excluded on the basis that this study is a first approximation intended to assess if and how significant the 'amelioration' factors potentially are within nuclear EROI calculations. The attention was not to generate an accurate and highly representative estimate of these factors and was therefore bounded in order to be manageable and readily comprehensible. As such, the calculations were formulated to focus on the factors involving the largest energy expenditures, for which underpinning data were readily available, and for which the underpinning features/systems could be readily simplified and described. This final point alludes to the fact that certain 'amelioration' factors will be complex to quantify due to a high degree of local variability when considered at the global scale, e.g., enabling civil engineering, which is highly dependent on the features and layouts of individual power plants and local codes of practice.

Several of the papers described in the literature review in Section 1 provide descriptions and quantifications applicable to this and equivalent factors (e.g., embedded energy linked to civil engineering materials). However, formulating an aggregated approach that robustly quantifies these factors in accordance with the approach of this paper (biophysical quantification of specific systems and processes) will likely need to be the subject of dedicated studies, which will build upon the 
figures presented in this study. This will align with the aim of this study, which is to outline a first approximation of the 'amelioration' factors, which are a foundation for further studies.

Table 11. Breakdown of the calculation methodology.

\section{Description of Factors}

- General description in the international context

- Outline of the primary features and complexities

- Nature of energy investments

\section{Assessment and Conclusion}

- Assessment of overall magnitude and contribution as an energy investment

- Feasibility of quantification

- Decision on inclusion in calculation

\section{Assessment of Data Requirements}

- Description of each datapoint to be included in the calculation

- Assumptions

- Exclusions

\section{Overall Calculation Approach}

- Each calculation will assess the energy expenditure associated with a particular activity, scaled up to the global scale over the whole duration of the 'nuclear system' i.e., a uniform set of 'amelioration' activities will be undertaken globally.

- A rate of energy use or embedded energy requirement will be multiplied by the total quantity of material requiring processing, moving etc.

- $\quad$ This will be multiplied by the numbers of decommissioning sites and geological disposal facilities worldwide.

- $\quad$ Ranges of figures will be applied to several key factors in order to provide a high-medium-low range of figures, to reflect the uncertainties associated with a large proportion of the data.

\section{Results}

Tables 12 and 13 present overarching data that apply to all of the calculations.

Table 12. Total number of nuclear power plants worldwide (high/medium/current).

\begin{tabular}{ccc}
\hline High Increase & Medium Increase & Current Situation \\
\hline 736 & 690 & 644 \\
\hline
\end{tabular}

Notes: The 'current situation' scenario figure is based on the figure presented by [1]; 417 operational power plants, 181 closed, and 46 under construction as of 2019. The 'medium increase' scenario assumes that a greater number (92, $100 \%$ more than the number approved in 2019) of power plants will be constructed in future, and the 'high increase' scenario assumes 138 (200\% more). Other nuclear sites (e.g., research and reprocessing facilities) are not included in these totals. 
Table 13. Total number of countries undertaking nuclear 'amelioration' activities (high/medium/low range).

\begin{tabular}{ccc}
\hline High & Medium & Low \\
\hline 30 & 26 & 15 \\
\hline
\end{tabular}

Notes: The 'high' scenario is based on the total number of countries with nuclear power programmes as presented by [56]. For the calculations relating to total number of geological disposal facilities to be constructed worldwide, the 'high' scenario (Table 13) assumes that each country with a nuclear programme will construct its own domestic geological disposal facility. The 'medium' scenario assumes countries with only one reactor will manage radioactive waste by other means, and the 'low' scenario assumes the same for countries with $\leq 5$ reactors in total. This acknowledges the fact that different nations have nuclear industries of varying sizes i.e., some countries only have a small number of reactors and therefore a limited total waste inventory, and therefore may not be able to justify construction of a dedicated domestic geological disposal facility and may manage waste via burial in shallow repositories, surface storage or equivalent. For the calculations relating to waste package manufacture, the same proportions are applied.

Tables 14-19 contain the calculations for each of the 'amelioration' factors included in this study.

Table 14. Input data and calculation for environmental remediation calculation.

\begin{tabular}{|c|c|c|c|}
\hline Excavator engine power $(\mathrm{J} / \mathrm{s})[57]$ & & $1.1 \times 10^{5}$ & \\
\hline \multirow{2}{*}{ Rate of extraction with $1 \mathrm{~m}^{3}$ capacity bucket ( $\mathrm{m}^{3} /$ hour) [seconds per $\mathrm{m}^{3}$ ] [58] } & Stiff clay & Gravel & Firm sand \\
\hline & $25(144)$ & $28.5(126)$ & $43(84)$ \\
\hline \multirow{2}{*}{ Total soil volume to be excavated per nuclear site $\left(\mathrm{m}^{3}\right)$} & High [57] & Medium [58] & Low [59] \\
\hline & $1.3 \times 10^{7}$ & $4.4 \times 10^{4}$ & $2.0 \times 10^{3}$ \\
\hline Total global energy requirement (TWh) & $4.21 \times 10^{1}$ & $1.16 \times 10^{-1}$ & $3.31 \times 10^{-3}$ \\
\hline
\end{tabular}

Note that this calculation is structured to produce a 'high' scenario that combines the soil with the slowest excavation rate (stiff clay) with the largest assumed excavation volume (as defined by [58]) and the highest number of nuclear power plants worldwide (refer to Table 12), with equivalent combinations applied for the 'medium/low' scenarios. Other combinations are possible, but this demonstrates the upper 'bounding' figure. * Multiplied by figures in Table 12.

Table 15. Input data and calculation for manufacture of 'passivated' waste packages.

\begin{tabular}{|c|c|c|c|}
\hline \multicolumn{4}{|l|}{ Cemented Packages } \\
\hline Cement density $\left(t / \mathrm{m}^{3}\right)[60]$ & \multicolumn{3}{|c|}{2.1} \\
\hline Cement per $4 m^{3}$ package $(t)[46]^{1}$ & \multicolumn{3}{|c|}{8.4} \\
\hline Energy requirement for cement manufacture (GJ/t) [61] & \multicolumn{3}{|c|}{3.8} \\
\hline \multirow{2}{*}{ Total number of packages per country } & High & Medium [46] ${ }^{2}$ & Low \\
\hline & $1.87 \times 10^{4}$ & $1.50 \times 10^{4}$ & $1.12 \times 10^{4}$ \\
\hline Total global energy requirement for cemented packages $(\mathrm{J})$ & $1.79 \times 10^{16}$ & $1.24 \times 10^{16}$ & $5.37 \times 10^{15}$ \\
\hline \multicolumn{4}{|l|}{ Vitrified Packages } \\
\hline Mass of vitrified product (kg) [62] & \multicolumn{3}{|c|}{400} \\
\hline Energy requirement for vitrification $(\mathrm{J} / \mathrm{kg})[63-65]^{3}$ & \multicolumn{3}{|c|}{$1.51 \times 10^{7}$} \\
\hline \multirow{2}{*}{ Total number of packages per country } & High & Medium [46] ${ }^{4}$ & Low \\
\hline & $3 \times 10^{3}$ & $2.4 \times 10^{3}$ & $1.8 \times 10^{3}$ \\
\hline Total global energy requirement for vitrified packages $(\mathrm{J})$ & $1.81 \times 10^{13}$ & $1.45 \times 10^{13}$ & $1.09 \times 10^{13}$ \\
\hline Total global * energy requirement for cemented and vitrified packages $(\mathrm{J})$ & $1.83 \times 10^{16}$ & $1.26 \times 10^{16}$ & $5.45 \times 10^{15}$ \\
\hline Total global energy requirement for cemented and vitrified packages (TWh) & 5.05 & 3.5 & 1.51 \\
\hline
\end{tabular}


Table 16. Input data and calculation for construction of geological disposal facilities.

\begin{tabular}{|c|c|c|c|}
\hline Tunnel diameter (m) [66] & & 5.5 & \\
\hline Tunnel face area $\left(\mathrm{m}^{2}\right)$ & & 23.76 & \\
\hline \multirow{2}{*}{ Total length of tunnel to be excavated $(\mathrm{m})$} & High & Medium [66] $^{1}$ & Low \\
\hline & $5.25 \times 10^{4}$ & $4.20 \times 10^{4}$ & $3.15 \times 10^{4}$ \\
\hline Total volume to be excavated $\left(\mathrm{m}^{3}\right)$ & $1.25 \times 10^{6}$ & $9.98 \times 10^{5}$ & $7.48 \times 10^{5}$ \\
\hline Energy requirement for Tunnel Boring Machine (TBM) $\left(\mathrm{TWh} / \mathrm{m}^{3}\right)[67,68]^{2}$ & $1.80 \times 10^{-8}$ & $1.50 \times 10^{-8}$ & $1.2 \times 10^{-8}$ \\
\hline Total global * energy requirement for construction of geological disposal facilities (TWh) & $6.74 \times 10^{-1}$ & $3.89 \times 10^{-1}$ & $1.35 \times 10^{-1}$ \\
\hline
\end{tabular}

Table 17. Input data and calculation for materials for engineered barriers.

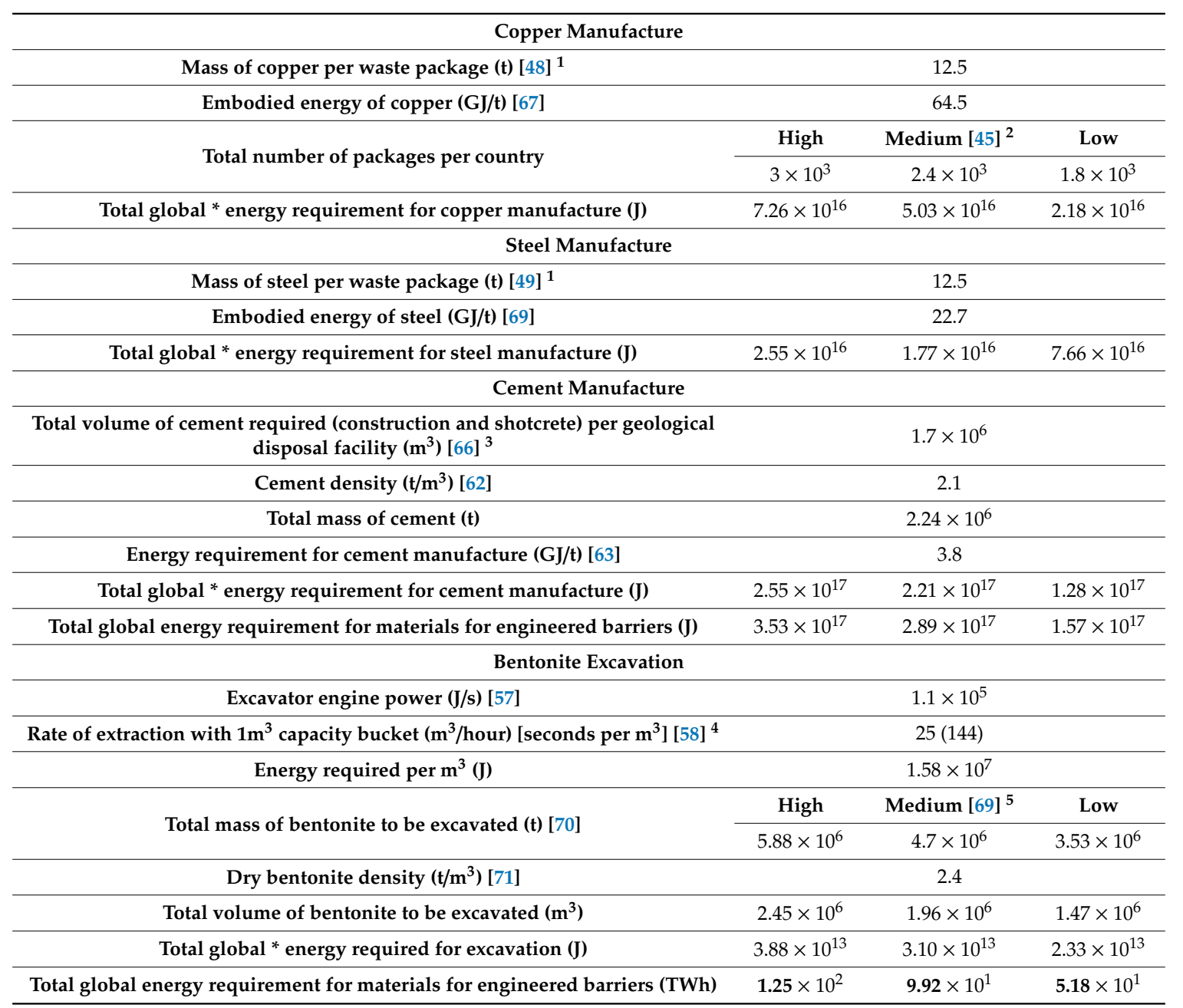

${ }^{1}$ Note Swedish-derived figure, based on the assumption that copper and steel comprise an equal proportion of the total KBS-3 canister mass. ${ }^{2}$ Note UK-derived figure; Total HLW Disposal Containers, and 'high/low' values are $25 \%$ more/less, respectively. ${ }^{3}$ Note UK-derived figure, based on sum of average required cement volumes (construction and shotcrete) calculated for different geological disposal facility concepts (i.e., for different potential host geologies). ${ }^{4}$ Note figure is stiff clay i.e., representative of bentonite. ${ }^{5}$ Note Swedish-derived figure; total bentonite requirement for geological disposal facility and 'high/low' values are $25 \%$ more/less, respectively. ${ }^{*}$ Multiplied by figures in Table 12. 
Table 18. Input data and calculation for international transport of bulk materials for engineered barriers.

\begin{tabular}{|c|c|c|c|}
\hline Total mass of bentonite required at each geological disposal facility $(t)[70]^{1}$ & \multicolumn{3}{|c|}{$4.7 \times 10^{6}$} \\
\hline Capacity of ore carrier ('Brazil'-class) (t) $[71]^{2}$ & \multicolumn{3}{|c|}{$4.00 \times 10^{5}$} \\
\hline Number of journeys required to transport total bentonite requirement ${ }^{3}$ & & 12 & \\
\hline \multirow{2}{*}{ Total length of journey $(\mathrm{km})$} & High & Medium $^{4}$ & Low \\
\hline & $1.10 \times 10^{4}$ & $5.50 \times 10^{3}$ & $2.75 \times 10^{3}$ \\
\hline Sailing time to cover distance (days) $[72]^{5}$ & 13 & 6.5 & 3.3 \\
\hline Fuel consumption $(\mathrm{t} / \mathrm{day})[73]^{5}$ & \multicolumn{3}{|c|}{150} \\
\hline Energy content of bunker fuel $(\mathrm{J} / \mathrm{t})[74]$ & \multicolumn{3}{|c|}{$4.00 \times 10^{10}$} \\
\hline Total global * energy requirement for transport of bentonite for engineered barriers (TWh) & 7.82 & 3.39 & 0.978 \\
\hline
\end{tabular}

Table 19. Total energy use for the 'amelioration' factors.

\begin{tabular}{cccc}
\hline Energy Requirement per 'Amelioration' Factor (TWh) & High & Medium & Low \\
\hline Environmental remediation (land/water/ecosystems) & $4.21 \times 10^{1}$ & $1.16 \times 10^{-1}$ & $3.31 \times 10^{-3}$ \\
\hline Manufacture of 'passivated' waste packages & 5.05 & 3.5 & 1.51 \\
\hline Construction of geological disposal facilities & 0.674 & 0.389 & 0.135 \\
\hline Materials for engineered barriers & 125 & 99.2 & 51.8 \\
\hline International transport of bulk materials for engineered barriers & 7.82 & 3.39 & 0.978 \\
\hline Total (TWh) & $\mathbf{1 8 1}$ & $\mathbf{1 0 7}$ & $\mathbf{5 4 . 4}$ \\
\hline
\end{tabular}

\section{Discussion}

\subsection{The 'Amelioration' Factors within the Nuclear System}

As described in Section 1, EROI can be defined in several different ways depending on the boundaries defined for a given energy system, and the range of energy investments and other factors that are incorporated into a given calculation [12]. In this study, the 'amelioration' factors have been characterised from a global, 'whole-system' perspective due to several features lending themselves to consideration as being relatively fixed and pre-determined, and less likely to be affected by different scenarios of future use of nuclear technology. Many of the factors have high connectedness with other energetic systems, and benefit from a large-scale perspective [17]. Additionally, these factors are also by definition the 'back end' of the nuclear system and so collective calculation and 'back-fitting' to EROI calculations may be an optimised methodology to address their role in the 'nuclear system'.

The centrepieces of decommissioning/waste management (geological disposal facilities) represent relatively fixed investments of energy. Different scenarios of future nuclear energy use (and therefore the overall quantities of waste requiring disposal) will not affect the energy investment for any given facility by a large degree relative to the 'fixed' energy investment requirement. In other words, there is a fixed investment of energy required to build the main features of a facility, and additional quantities of waste requiring disposal are unlikely to add to that cost by a large fraction.

Similarly, the waste products requiring passivation in many jurisdictions (e.g., the UK) already largely exists as a result of legacy power plants and other historical applications of nuclear technology, and the total may therefore not be affected by different future scenarios of nuclear energy use by a large degree. In other words, even in future scenarios where the use of nuclear technology is expanded significantly, the additional waste generated will likely not comprise a significant fraction of the national totals (which is attributable to an extent by technological improvements resulting in less intensive generation of wastes since the inception of nuclear technology). It is acknowledged that it is assumed here that a geological disposal facility will be available in future, but as noted in Section 2.1 
this is the policy in the majority of nations with nuclear programmes, is nearing implementation in several nations, and does not appear to have any fundamental technical barriers to being achieved.

Given these unique characteristics of the 'amelioration' factors, the figures presented in this study for the calculation of nuclear EROI could be utilised differently. A whole-system approach would add ranges of figures for different 'enabling' factor scenarios (based on historical figures combined with different ranges of future nuclear energy usage) to the 'amelioration' factors in order to calculate the denominator of the EROI equation. The total nuclear energy output (the numerator of the equation) would similarly be based on total output to date, added to figures for different scenarios, and projections of future nuclear energy use. Alternatively, the total energy requirement of the 'amelioration' factors could be applied to energy systems with smaller system boundaries (i.e., specific time periods or locations) with an underpinned correction factor, i.e., a calculated fraction of the global 'amelioration' total could be applied to EROI for a specific location at a given point in time.

The calculation of an EROI figure is not attempted in this study as the primary intent was to undertake a first approximately of a specific problem that had not been previously considered (the detail of the 'amelioration factors'), as a foundation for further study. The complexities associated with application of the 'amelioration' factors to the calculation of nuclear EROI are also outside the boundaries of this study, but the preceding discussion is intended to form a basis for future consideration of that problem.

It is noted that even the most pessimistic figure for the 'grand total' of the 'amelioration' figures is small in relation to total contemporary anthropogenic energy flows (though this contrast may potentially be less pronounced for future total flows, as indicated by [9]); total global energy consumption (all forms of primary energy) in 2017 was $1.63 \times 10^{5} \mathrm{TWh}$ [74], which is three orders of magnitude greater than the 'high' scenario of the 'amelioration' factors. This is of course a different consideration to that of EROI (which is a ratio of the marginal gain of a given energy source), and future refining and improvement of the 'amelioration' factors may indicate that the total energy requirement is significantly greater than presented here. However, in absolute terms, the energy requirement of decommissioning all nuclear facilities and disposing of all radioactive waste in geological disposal facilities as calculated here, is the equivalent of only a small fraction of human energy use in recent years.

\subsection{Comparison of 'Enabling' and 'Amelioration' Factors}

This paper makes the case that any realistic calculation of EROI for nuclear technology should incorporate a comprehensive and holistic assessment of the nuclear system that fully considers both the 'enabling' and 'amelioration' factors. Therefore, the assessment and quantification of the 'amelioration' factors to a greater level of detail than has been attempted in any previous studies was an important task in improving EROI figures. We have presented a 'first approximation' of the overall magnitude of the energy investment that the 'amelioration' factors represent globally. This therefore offers the opportunity to make a broad comparison with the magnitude of the 'enabling factors', and to assess the relative importance of these factors.

Although Section 1.1.2 identifies that Weissbach et al. [23] has some controversies linked to its methods and conclusions, it does provide a set of figures that are suitable for the approximated calculation of the global figure for the 'enabling' factors. Table 20 presents these figures [23] against the quantitative output of this paper. 
Table 20. Approximation of 'enabling' factors and ratio with 'amelioration' factors.

\begin{tabular}{|c|c|c|c|c|}
\hline $\begin{array}{l}\text { Enabling } \\
\text { Factors Total } \\
\text { (TWh) }^{1}\end{array}$ & $\begin{array}{l}\text { Total Number of Future Nuclear } \\
\text { Power Plants Worldwide } \\
\text { (High/Medium/Low) }^{2}\end{array}$ & $\begin{array}{l}\text { Total 'Enabling' } \\
\text { Energy Requirement } \\
\text { (TWh) }\end{array}$ & $\begin{array}{c}\text { Total 'Amelioration' } \\
\text { Energy Requirement } \\
\text { (TWh) }\end{array}$ & $\begin{array}{c}\text { 'Enabling'/ } \\
\text { 'Amelioration' Ratio }\end{array}$ \\
\hline \multirow{3}{*}{8.2} & 736 & 6035.2 & 181 & $33: 1$ \\
\hline & 690 & 5658 & 107 & $53: 1$ \\
\hline & 644 & 5280 & 54 & $97: 1$ \\
\hline
\end{tabular}

${ }^{1}$ This is calculated by the addition of three factors derived from [23]. These three factors cover the 'nuclear system' subsystems describing the 'enabling' factors as per Section 1.2 (derived from [22]), and are: Fuel-related energy demand' (5.2 TWh), which corresponds to i-v and ix; 'Construction energy demand' (1.1 TWh), which corresponds to vi; and 'Maintenance energy demand'(1.9 TWh), which corresponds (approximately) to vii. The total figure of 8.2 TWh relates to an individual, representative nuclear power plant, and is therefore taken to be representative of each power plant worldwide. These figures used to calculated this 'enabling' factors total are caveated as being approximations, and also originate from [23], which as previously noted has associated controversies [24,33]. ${ }^{2}$ Taken from Table 12, these multipliers are used to scale the individual power plant figures provided by [23] to the global scale $^{3}$. The topmost figure ( $181 \mathrm{TWh}$ ) is the grand energy total for the 'High' scenario of the 'amelioration' factors (taken from Table 19), which is compared to the 'enabling' total multiplied by the 'High' scenario for total number of future nuclear power plants (taken from Table 12). The corresponding 'Medium' and 'Low' scenarios (from Tables 12 and 19) are used to calculate the figures below this line.

Based on the figures presented in Table 20, the 'enabling' factors are approximately 1.5-2 orders of magnitude larger than the (first approximation of the) 'amelioration' factors. Therefore, based on these sources and calculations, the contribution of the 'amelioration' factors is a relatively minor contribution to the denominator of the EROI equation in comparison to the 'enabling' factors. The following statements should be noted in light of this assessment:

If it is the case that the 'amelioration' factors are a minor contribution to the energy costs linked to nuclear EROI, detailed breakdown and analysis of these factors was required to address the gap in the literature, and robustly demonstrate and underpin their minor contribution;

- This study has broken down the 'amelioration' factors to a greater level of detail and quantification than any previous studies have attempted, but the analysis indicates that this breakdown (in its current form) would not significantly alter any of the EROI values calculated in previous studies (i.e., the 'amelioration' factors are not large enough to reduce EROI numbers by a significant degree);

- The calculations undertaken for the 'amelioration' factors in this study are explicitly a 'first approximation' that incorporate multiple approximations, simplifications, and exclusions;

- Future studies that address the approximations and exclusions, and increase the 'resolution' with which the calculations assess local factors (i.e., energy for civil engineering at individual nuclear sites, multiplied up to global scale), may demonstrate the energy requirements of the 'amelioration' factors to be greater and the ratio of the factors to therefore be closer;

- Conversely, the lower overall EROI figures presented in other studies [12,35] (see Table 1) may imply even greater 'enabling' energy costs, and therefore a potentially even lower (i.e., negligible) contribution from the 'amelioration' factors calculated in this study to overall EROI. The different ranges of 'enabling' energy costs will need to be analysed against improved 'amelioration' figures as part of future work;

- Even if the contribution of the 'amelioration' factors is demonstrated to remain relatively small after further investigation, it would nonetheless be recommended for these factors to be accounted for in future nuclear EROI calculations. This is due to the societal importance of EROI and its potential to decrease in future [12,38], which could lead to the narrowing of overall EROI 'margins', therefore even energy costs that only contribute on the order of $1-10 \%$ of the total energy costs may still have significance; and

- There may be additional factors that could increase the relative importance of the 'amelioration' factors in the future (see following subsection). 


\subsection{Systemic Aspects of Nuclear EROI}

At the 'whole system' scale that this study considers, there is a strong temporal element that differentiates the 'enabling' and 'amelioration' factors, which results from a staggering of the timing of the peak energy requirement of the 'amelioration' factors relative to the 'enabling' factors. Much of the large-scale 'enabling' of the nuclear industry (R\&D of nuclear technology, construction of facilities and infrastructure, etc.) was 'front loaded' and took place in the early decades of the industry (approximately 1950s-1970s). In contrast, little of the energy costs linked to the 'amelioration' factors have started to be incurred during more recent timeframes, and on the current pathway will reach a peak in the future [1,74].

This contrast may be significant from a systemic perspective due to the alignment with the availability of high-EROI energy sources at global scale. Nuclear fission is by definition 'high-technology' and its initial comprehension and development relied on a global system capable of high-energy activities such as large-scale resource appropriation, engineering, and scientific collaboration. These 'enabling' energy costs were incurred to a significant degree during a period in which high-EROI energy sources were readily available, exemplified by the timeframe in which 'upward limbs' of the various metrics characterising 'the Great Acceleration' [28,75] are observed.

The increasing prevalence of the 'amelioration' factors in future will create increased energy and material demands in the form of dedicated industries and branches of government (nested within existing systems) to facilitate e.g., the global management of radioactive waste and construction of geological disposal facilities. In contrast to the 'enabling' factors, a large proportion of these 'amelioration' energy costs will be incurred (and will likely peak) during a period when human society at the global scale is likely to be experiencing declining global EROI [12,38] and increasing energy resource scarcity (e.g., from decreasing availability of low cost hydrocarbons) [9]. The energetic costs of the 'amelioration' factors could therefore be interpreted as having a higher 'weighting' relative to the 'enabling' factors, regardless of their relative absolute values [76].

An additional manifestation of temporal effects may be the impact on the nuclear decommissioning strategy that is incumbent in many nations currently, namely the deferral of the final dismantling of redundant reactor and bioshield structures. The primary incentive for this strategy is based on the economic discounting of costs, but a continuing global trend towards reducing government interest rates means that the apparent financial benefits of transferring the liabilities to the future are being largely nullified, potentially leading to reversal of this strategy [77]. This may be beneficial in terms of the timing of decommissioning and the current availability of relatively high EROI energy sources.

It is the future growth in the energetic importance of the 'amelioration' factors that is the basis for potentially greater 'weighting', however certain aspects of the 'enabling' factors are also likely be subject to equivalent temporal effects in parallel to the 'amelioration' factors. In particular, there are limited and poorly distributed reserves of higher-grade uranium ore globally [78]. This had resulted from intensive global mining of this resource since the inception of the nuclear age, and the remaining reserves of high-grade ore will deplete further as extraction continues. The material throughput (and therefore energy demand) increases significantly at increasingly lower grades. As noted in regard to the 'amelioration' factors, this increasing demand for energy to source uranium will occur during the timeframes when global EROI is likely to be experiencing declines. Future global declines in EROI are therefore likely to have significant knock-on effects for the overall EROI of nuclear energy.

\section{Conclusions}

Civil nuclear fission energy has contributed to global energy supply for approximately 70 years, but the EROI that this energy source provides has only been incompletely described in the existing literature. The definition of a value for nuclear EROI is vital because complex global society demands a minimum value, and an expansion of nuclear capacity has been mooted to assist with GHG emissions reductions. Challenges with the definition and quantification of nuclear EROI arise from the general complexities associated with EROI calculations, namely definition of energy system boundaries and 
what additional factors to include, but also the interplay of energy costs in the different parts of the nuclear system. In terms of energy costs and investments, the nuclear system can be considered to comprise two parts, which are those that underpin and enable the operation of nuclear technology (the 'enabling' factors) and the externalities that result from the use of nuclear technology, and which must be addressed through appropriate means (the 'amelioration' factors). Existing studies that have considered nuclear EROI have generally emphasised the role of the 'enabling' factors, with the role and level of detail apportioned to the 'amelioration' factors being less well defined. This study advocates that the 'amelioration' factors are a biophysical necessity, are complex and multi-faceted, and are due to grow in importance in future, and as such need to be defined in greater detail and given consideration proportional to their role alongside the 'enabling' factors if a realistic nuclear EROI value is to be calculated. Indeed, these 'amelioration' factors should themselves be considered as 'enabling' within the nuclear system. Existing international 'amelioration' projects clearly demonstrate the magnitude and complexity of this aspect of the 'nuclear system'.

Interpretation of the components of the 'nuclear system' [22] led to the identification of 12 relevant 'amelioration' factors. This study considered five of these, which were selected on the basis of likely being significant energy investments, and which lend themselves to definition and calculation of first approximation of their associated energy costs. A further four of these factors were classified as likely being significant energy investments but which presented greater complexity in terms of calculation and global scaling and will therefore be quantified as part of future work to refine the 'amelioration' factors overall.

The factors included in the calculation were: Environmental remediation (land/water/ecosystems); manufacture of 'passivated' waste packages; construction of geological disposal facilities; materials for engineered barriers; and international transport of bulk materials for engineered barriers. Due to the high complexity of all of these factors, the calculations were necessarily simplified with numerous assumptions, and exclusions; this will nonetheless offer a significantly improved assessment of these factors over and above that attempted by previous studies, and will form the foundation for future work to refine and improve this calculation (and therefore allow calculation of an overall EROI figure more reflective of reality).

The ranges of total energy costs associated with the 'amelioration' factors was compared with published figures for the 'enabling' factors. The calculated ratios showed that the contribution of the 'amelioration' factors studied in the work, to the energy costs associated with the use nuclear technology, is low compared to the contribution of the 'enabling' factors.

The findings of this calculation are however caveated as being based on the 'first approximation' figures for the 'amelioration' factors, and 'enabling' factors derived from a study with noted controversies [20-22]. In future, these figures should be expanded to include omitted factors and increased in terms of the granularity of contributing numbers to account for a full range of energy costs at global scale. As such, these future refined calculations for the 'amelioration' factors, along with expanded consideration of 'enabling' factors, may indicate that they are of greater significance (i.e., a closer ratio with the 'enabling' factors) for nuclear EROI than has been indicated here.

Furthermore, there is a systematic aspect that could potentially increase the significance of the 'amelioration' factors. The EROI of global energy sources has been particularly high for approximately 70 years [28] but may undergo a significant future reduction within the timeframe in which the 'amelioration' factors for nuclear will require the greatest energy input; this could effectively create an increased 'weighting' for these factors in terms of energy costs in the future.

Author Contributions: Conceptualization, N.K. and A.J.; methodology, N.K.; validation, A.J.; formal analysis, N.K.; writing—original draft preparation, N.K.; writing-review and editing, A.J. All authors have read and agreed to the published version of the manuscript.

Funding: This research received no external funding.

Acknowledgments: The authors would like to thank the three reviewers who provided useful comments that have improved both the quality and comprehensive nature of this paper. 
Conflicts of Interest: The authors declare no conflict of interest.

\section{Appendix A. Assessment of the 'Amelioration' Factors}

Table A1. Reactor defueling.

\begin{tabular}{|c|c|}
\hline Discussion & Conclusion \\
\hline $\begin{array}{l}\text { Nuclear fuel is handled (emplaced in and removed from } \\
\text { reactor cores) by dedicated, remotely operated fuelling } \\
\text { machines which are used throughout the operational period, } \\
\text { and also for the removal of the final fuel load. } \\
\text { Fuelling/de-fuelling in light water reactors (LWRs) is } \\
\text { undertaken in single campaigns whilst the reactor is shut } \\
\text { down, whilst heavy water reactors (HWRs) and gas-cooled } \\
\text { reactors (GCRs) can be fuelled/defueled whilst operational. } \\
\text { As such, the methods, technologies used, and time required } \\
\text { to defuel the mix of power plants internationally varies } \\
\text { considerably [79]. }\end{array}$ & $\begin{array}{l}\text { Likely not a significant energy } \\
\text { investment due to use of standard } \\
\text { equipment and small volumes of } \\
\text { material handled. } \\
\text { - } \quad \text { Quantification will need to account for } \\
\text { variation in fuel handling technology } \\
\text { and duration of defueling period. } \\
\text { - To be quantified as part of future work }\end{array}$ \\
\hline
\end{tabular}

Table A2. Remediation/dismantling/demolition of redundant structures/infrastructure.

\begin{tabular}{|c|c|}
\hline Discussion & Conclusion \\
\hline $\begin{array}{l}\text { The currently preferred approach for the decommissioning of } \\
\text { nuclear facilities that has been adopted internationally is to } \\
\text { demolish and clear as much infrastructure as possible soon } \\
\text { after shutdown and defueling, and to then leave the most } \\
\text { radiologically contaminated areas (e.g., reactor pressure } \\
\text { vessel/core, biological shields, packaged waste) in a quiescent } \\
\text { state for a prolonged period (multiple decades), for clearance } \\
\text { at the end of this period. This approach (labelled SAFSTOR } \\
\text { in the US and Care and Maintenance in the UK) is primarily } \\
\text { to gain benefits from radioactive decay and financial } \\
\text { discounting of decommissioning funds. The infrastructure } \\
\text { that is cleared in the short term (e.g., turbine hall, } \\
\text { administration buildings) varies according to the design and } \\
\text { layout of individual power plants and is } \\
\text { remediated/decontaminated and dismantled/demolished } \\
\text { using a wide range of different approaches and } \\
\text { techniques [40,80]. }\end{array}$ & $\begin{array}{l}\text { - Likely to be a significant energy } \\
\text { investment due to numbers of redundant } \\
\text { facilities and waste produced. } \\
\text { Quantification will need to account for } \\
\text { individual features and conditions of } \\
\text { infrastructure, and different approaches } \\
\text { employed for decommissioning at } \\
\text { hundreds of international power plants } \\
\text { - To be quantified as part of future work }\end{array}$ \\
\hline
\end{tabular}

Table A3. Environmental remediation (land/water/ecosystems).

\begin{tabular}{|c|c|}
\hline Discussion & Conclusion \\
\hline $\begin{array}{l}\text { Nuclear facilities can cause radioactive and non-radioactive } \\
\text { contaminants to enter the adjacent environment, either } \\
\text { deliberately through controlled discharges, } \\
\text { or non-intentionally through leaks and accidents. } \\
\text { Environments most likely to be affected are land (soil), water } \\
\text { and ecosystems, and contaminants in soil are most likely to } \\
\text { be persistent. A range of contaminated soil remediation } \\
\text { techniques have been developed and employed outside the } \\
\text { nuclear industry (e.g., thermal treatment, bioremediation) } \\
\text { but many of these are generally less effective for } \\
\text { contaminants such as radionuclides, so civil } \\
\text { engineering-based remediation techniques (mainly 'dig and } \\
\text { dump'; excavation and removal to specialised low-level } \\
\text { waste management facilities) has been frequently employed } \\
\text { for remediation of radioactively contaminated land [81]. }\end{array}$ & $\begin{array}{l}\text { - Likely to be a significant energy } \\
\text { investment due to likely large extent of } \\
\text { contaminated soil at nuclear } \\
\text { facilities internationally. } \\
\text { 'Dig and dump' is a relatively simple } \\
\text { remediation technique based on bulk } \\
\text { excavation so suitable references } \\
\text { are available. } \\
\text { - Included in calculation }\end{array}$ \\
\hline
\end{tabular}


Table A3. Cont.

\section{Calculation}

The energy consumption of 'dig and dump' will be based on:

- The energy consumption (power) of a representative excavator

- The time required to excavate given volumes in different soil types

- $\quad$ The energy required per unit volume of soil (based on excavator power and time required)

- A range of values for the quantities of soil requiring excavation

- The total number of international sites where 'dig and dump' will be required

Calculation assumptions:

- All nuclear power plant sites worldwide will have some contaminated land requiring remediation, and the ranges of quantities of soil requiring excavation are based on high, medium and low volumes of soil at representative UK nuclear sites.

- $\quad$ 'Dig and dump' is the only remedial technique applied.

Calculation exclusions:

- Onward transport, handling and other management of excavated soil (at dedicated waste facilities)

- $\quad$ Secondary enabling factors (project set-up and close-out, construction of infrastructure)

Table A4. Enabling civil engineering.

\begin{tabular}{|c|c|}
\hline Discussion & Conclusion \\
\hline $\begin{array}{l}\text { Decommissioning of a shutdown nuclear power plant/facility } \\
\text { is highly complex, regulated and risky, and will therefore in } \\
\text { most cases require new infrastructure to be constructed to } \\
\text { enable work to be carried out safely and effectively. This will } \\
\text { comprise a wide range of civil engineering, including the } \\
\text { construction of new structures to permit at-height access, } \\
\text { waste processing facilities, and external infrastructure such } \\
\text { new access roadways and upgrade of port facilities. The } \\
\text { nature and extent of these facilities will be highly tailored to } \\
\text { the individual design and requirements of power plants } \\
\text { undergoing decommissioning, and local conditions and } \\
\text { regulation [40]. }\end{array}$ & $\begin{array}{l}\text { - Likely to be a significant energy } \\
\text { investment due to extent and nature of } \\
\text { enabling infrastructure required. } \\
\text { Quantification will need to account for } \\
\text { individual features, and different } \\
\text { approaches employed for } \\
\text { decommissioning at hundreds of } \\
\text { international power plants } \\
\text { - To be quantified as part of future work }\end{array}$ \\
\hline
\end{tabular}

Table A5. Manufacture of 'passivated' waste packages.

\begin{tabular}{|c|c|}
\hline Discussion & Conclusion \\
\hline $\begin{array}{l}\text { Radioactive waste in most cases undergoes 'passivation' } \\
\text { (also 'conditioning') within specialist manufacturing facilities } \\
\text { to create 'waste packages' (comprising waste, conditioning } \\
\text { and capping matrix, and container) that are inert and } \\
\text { immobile, and therefore suitable for long-term storage and } \\
\text { eventual geological disposal. Intermediate-level waste (ILW) } \\
\text { is often passivated within a cement matrix, and high-level } \\
\text { waste (HLW, where reprocessing is undertaken) undergoes a } \\
\text { process called 'vitrification' to create a borosilicate glass } \\
\text { monolith }[40,46,82]\end{array}$ & $\begin{array}{l}\text { - Likely to be a significant energy } \\
\text { investment due to the energetic demands } \\
\text { of the manufacturing processes and large } \\
\text { numbers of packages required. } \\
\text { - } \quad \text { Manufacturing processes are } \\
\text { well-established and have equivalents } \\
\text { outside of the nuclear industry, so } \\
\text { suitable references are available. } \\
\text { Included in calculation }\end{array}$ \\
\hline
\end{tabular}


Table A5. Cont.

\begin{tabular}{|c|c|}
\hline \multicolumn{2}{|l|}{ Calculation } \\
\hline \multicolumn{2}{|c|}{$\begin{array}{l}\text { The energy consumption of the manufacture of 'passivated' waste packages will be divided up into } \\
\text { 'cementation' and 'vitrification'. The energy consumption will be based on: }\end{array}$} \\
\hline \multicolumn{2}{|c|}{$\begin{array}{l}\text { - The quantity of cement/vitrified product in each waste package. } \\
\text { - The energy requirement per unit quantity of cement/vitrified product. } \\
\text { - The total number of packages of each type that are to be manufactured per country. } \\
\text { - The range of countries in which 'passivated' waste packages are to be manufactured. }\end{array}$} \\
\hline \multicolumn{2}{|c|}{$\begin{array}{l}\text { - Cementation is applied in all countries with nuclear programmes for ILW passivation. } \\
\text { - Vitrification is applied where passivation of HLW resulting from spent fuel reprocessing is required. } \\
\text { - } \quad \text { Reprocessing has been undertaken by a number of countries with nuclear programmes historically and } \\
\text { continues to be used by some nations. } \\
\text { In other nations spent nuclear fuel is not reprocessed and fuel rods undergo long-term storage pending } \\
\text { direct disposal (i.e., without any further treatment), but in some cases spent fuel has been exported } \\
\text { overseas for reprocessing. } \\
\text { - Due to this complexity, it is assumed that half of the number of (the range) countries with nuclear } \\
\text { programmes have contributed to the generation of HLW that requires vitrification. } \\
\text { The waste handling, processing and waste package manufacturing processes are identical (e.g., in terms } \\
\text { of the energy expenditure of the vitrification process) in each country i.e., the processing plants are the } \\
\text { same and the waste package specifications do not vary internationally. }\end{array}$} \\
\hline \multicolumn{2}{|c|}{$\begin{array}{l}\text { - Waste packages passivated by other techniques and materials. } \\
\text { - The energy requirements for the handling of the waste, manufacture of the waste containers (e.g., metallic } \\
\text { drums and boxes), and construction and decommissioning of the manufacturing facilities. }\end{array}$} \\
\hline Discussion & Conclusion \\
\hline $\begin{array}{l}\text { International nuclear programmes will in many cases require } \\
\text { that radioactive waste (in the form of 'passivated' waste } \\
\text { packages) undergoes storage. This is largely due to the } \\
\text { 'time-lag' in the production of radioactive waste and the } \\
\text { availability of geological disposal facilities necessitating the } \\
\text { interim/buffer storage of waste/waste packages. Due to the } \\
\text { necessity to maintain the packages (which are generally } \\
\text { engineered to high specifications) in optimal condition for } \\
\text { eventual disposal, a proportion of these stores are operated } \\
\text { under controlled conditions e.g., active cooling. This may be } \\
\text { for extended periods (decades) and for bulk numbers of } \\
\text { packages [40,46]. }\end{array}$ & $\begin{array}{l}\text { - Likely to be a significant energy } \\
\text { investment due to the large size/number } \\
\text { of stores and extended periods } \\
\text { of operation. } \\
\text { Quantification will need to account for } \\
\text { local requirements, variation in active } \\
\text { controls required, and uncertainty over } \\
\text { duration of storage } \\
\text { periods internationally. } \\
\text { To be quantified as part of future work }\end{array}$ \\
\hline
\end{tabular}


Table A7. Construction of geological disposal facilities.

\begin{tabular}{|c|c|}
\hline Discussion & Conclusion \\
\hline $\begin{array}{l}\text { A generic geological disposal facilities will comprise "... a } \\
\text { highly-engineered facility, located deep underground, where the } \\
\text { waste will be isolated within a multi-barrier system ...", and will } \\
\text { comprise surface facilities, vertical shafts, a drift access } \\
\text { tunnel, and at the depth of the operational area a large } \\
\text { complex of disposal tunnels and vaults, } \\
\text { and support/operational spaces [66]. The excavation of the } \\
\text { underground infrastructure is undertaken by a combination } \\
\text { of tunnel boring machine (TBM) and drill and blast } \\
\text { techniques, according to factors such as required tunnel } \\
\text { orientation, geometry and size in different parts of the } \\
\text { facility }[66,83] \text {. }\end{array}$ & $\begin{array}{l}\text { - Likely to be a significant energy } \\
\text { investment due to the requirement for } \\
\text { the excavation of significant lengths of } \\
\text { tunnel in potentially hard-rock geology } \\
\text { at depth. } \\
\text { The energy requirement of tunnelling is } \\
\text { well-defined due to the large number of } \\
\text { tunnelling projects that have been } \\
\text { carried out internationally. } \\
\text { Included in calculation }\end{array}$ \\
\hline
\end{tabular}

\section{Calculation}

The energy required to excavate the tunnels in a representative geological disposal facility will be based on:

- The total length of tunnel requiring excavation.

- The diameter/tunnel face area of a 'representative tunnel'.

- The total volume of rock that will be excavated.

- $\quad$ The energy required per unit volume rock to operate a representative TBM.

- The total energy for excavation of total tunnel length required for the geological disposal facility.

- The range of the number of geological disposal facilities to be constructed

Calculation assumptions:

- $\quad$ Excavation using TBMs will be applied for the whole facility.

- Geology is uniform over the whole volume of rock in which the facility is constructed.

- The tunnel diameter and geometry are constant throughout the facility.

Calculation exclusions:

- Geological investigations to characterise the site prior to site selection and commencement of tunnelling.

- Removal and management of spoil.

- $\quad$ Other aspects of construction e.g., tunnel wall stabilisation (note that tunnel 'shotcreting' is included in the engineered barrier calculation in Table 16), surface facilities.

Table A8. Materials for engineered barriers.

\begin{tabular}{|c|c|}
\hline Discussion & Conclusion \\
\hline $\begin{array}{l}\text { Geological disposal relies on a multi-barrier concept } \\
\text { (engineered structures and geological features) to passively } \\
\text { isolate and contain the hazardous contaminants in } \\
\text { radioactive waste over prolonged time periods. The } \\
\text { materials used in generic engineered barrier systems are } \\
\text { bentonite }{ }^{1} \text {, cement, and metallic containers. Metallic } \\
\text { containers are to be applied as barriers for heat-generating } \\
\text { (spent fuel and HLW) waste packages along with bentonite, } \\
\text { which will also be applied for void-filling ('backfilling') } \\
\text { purposes, and cement will be applied as barrier, for } \\
\text { 'backfilling' material around non heat-generating waste (ILW) } \\
\text { packages, and as shotcrete for tunnel construction. The types } \\
\text { of metallic containers applied will be dependent on the host } \\
\text { geology in which disposal facilities are constructed } \\
\text { worldwide [66]. The use of either the KBS-3 or mild steel } \\
\text { canister concepts for future disposal facilities in 'higher } \\
\text { strength rock' and 'lower strength sedimentary rock', } \\
\text { respectively is planned [46]. }\end{array}$ & $\begin{array}{l}\text { - Likely to be a significant energy } \\
\text { investment due to large } \\
\text { quantities/numbers of high-specification } \\
\text { materials/manufactured items required. } \\
\text { - Obtaining bentonite will be based on } \\
\text { bulk excavation so suitable references } \\
\text { are available. } \\
\text { - Cement and manufacture of metallic } \\
\text { containers will be based well-established } \\
\text { techniques, so suitable references } \\
\text { are available. } \\
\text { Included in calculation }\end{array}$ \\
\hline
\end{tabular}


Table A8. Cont.

\section{Calculation}

The energy consumption of obtaining bentonite will be based on:

- $\quad$ The energy consumption (power) of a representative excavator.

- $\quad$ The time required to excavate given volumes of bentonite.

- $\quad$ The energy required per unit volume of bentonite (based on excavator power and time required).

- The range of total volume of bentonite required for a geological disposal facility.

- The range of the number of geological disposal facilities to be constructed.

The energy consumption of cement will be based on:

- The total mass of cement required at a geological disposal facility.

- The energy requirement per unit quantity of cement.

- The range of the number of geological disposal facilities to be constructed.

The energy consumption of the manufacture of metallic containers will be based on:

- $\quad$ The quantity of steel/copper required per package.

- The energy requirement per unit quantity of steel/copper.

- The range of the number of packages required for each geological disposal facility.

- The range of the number of geological disposal facilities to be constructed.

Calculation assumptions:

- $\quad$ The KBS-3 concept requires the manufacturing of three separate components, so is energetically demanding and therefore assumed as the system used in all geological disposal facilities worldwide (as a conservatism).

- $\quad$ KBS-3 is designed for the direct disposal of spent fuel but is assumed it can be applied for the disposal of vitrified HLW waste packages as well.

- $\quad$ The amount of concrete required will be based on an averaged value for different host geologies in generic UK designs.

Calculation exclusions:

- $\quad$ The energy requirements for metallic containers for ILW/HLW waste packages.

\footnotetext{
${ }^{1}$ A clay consisting of smectite (montmorillonite, and various accessory clay minerals) with favourable swelling and hydraulic conductivity characteristics [69].
} 
Table A9. Long-term operation of facilities.

\begin{tabular}{|c|c|}
\hline Discussion & Conclusion \\
\hline $\begin{array}{l}\text { The emplacement of radioactive waste packages within } \\
\text { geological disposal facilities will be a highly complex } \\
\text { operation that will occur continuously over the course of } \\
\text { multiple decades. Numerous active and passive systems will } \\
\text { be constructed/installed, operated, maintained and } \\
\text { decommissioned to permit operation of the facility under } \\
\text { highly regulated conditions. This will include (but will not } \\
\text { be limited to) systems to permit the movement/emplacement } \\
\text { of radioactive waste packages, to permit the construction of } \\
\text { new tunnels, to control groundwater ingress, the provision of } \\
\text { active ventilation, and monitoring (e.g., of criticality, } \\
\text { atmospheric composition, structural conditions) [66,84]. } \\
\text { Highly complex projects such as the implementation of } \\
\text { geological disposal facilities will generate very large } \\
\text { quantities of digital data (e.g., from geological investigations, } \\
\text { engineering specifications, waste package records, } \\
\text { management of waste package movements) which will } \\
\text { require processing, storage, and continuous access. [85] } \\
\text { indicates that annual electricity consumption for IT data } \\
\text { centres in the US alone in the } 10^{2} \text { TWh range from the 2010s } \\
\text { onwards, therefore the energy expenditure associated with } \\
\text { the management of data to support nuclear 'amelioration' } \\
\text { activities will need to be factored into quantification. } \\
\text { Other factors that may apply to power plants undergoing } \\
\text { decommissioning and support infrastructure include lighting } \\
\text { and space heating, vehicles, etc. The energy consumption of } \\
\text { systems of this nature will be small at any given point in time, } \\
\text { but over long operational periods these may aggregate into } \\
\text { significant expenditures. These systems are small, dispersed } \\
\text { and locally variable nature, but their overall, aggregate } \\
\text { contribution could potentially be significant at global scale }\end{array}$ & $\begin{array}{l}\text { Likely to be a significant energy } \\
\text { investment due to the large size of } \\
\text { geological disposal facilities, multiple } \\
\text { active systems and long } \\
\text { operational period. } \\
\text { Quantification will need to account for } \\
\text { variation in size, features, operational } \\
\text { models and other local factors } \\
\text { internationally, and the operational } \\
\text { period being uncertain and likely } \\
\text { variable between different countries. } \\
\text { To be quantified as part of future work. }\end{array}$ \\
\hline
\end{tabular}

Table A10. International transport of bulk materials for engineered barriers.

\begin{tabular}{|c|c|}
\hline Discussion & Conclusion \\
\hline $\begin{array}{l}\text { As described in Table 16, different materials will be required } \\
\text { for engineered barriers in each of the countries constructing } \\
\text { geological disposal facilities, which in many cases will } \\
\text { require bulk imports of materials. Bentonite is likely to be } \\
\text { used extensively in geological disposal facilities of different } \\
\text { designs due to its unique properties and will be required in } \\
\text { very large quantities ([46,70] calculate that they will require a } \\
\text { total of } 4.7 \text { million tonnes in total for the Swedish repository). } \\
\text { The global distribution of bentonite reserves suitable for use } \\
\text { in GDFs (primarily sodium bentonite) are spatially } \\
\text { heterogeneous [70], therefore the majority of nations looking } \\
\text { to implement geological disposal will need to import some or } \\
\text { all of the total quantity of bentonite required. The transport } \\
\text { of bulk materials such as this over long distances will } \\
\text { necessarily require transport by sea, likely in container ships, } \\
\text { bulk ore carriers, or equivalent. }\end{array}$ & $\begin{array}{l}\text { - Likely to be a significant energy } \\
\text { investment due to the large quantities of } \\
\text { materials requiring transport over } \\
\text { intercontinental distances. } \\
\text { The requirement for bentonite is well } \\
\text { established and is likely to constitute the } \\
\text { largest bulk material requirement. } \\
\text { The global bulk shipping industry can } \\
\text { provide the basis for calculating the } \\
\text { energy expenditure of } \\
\text { bentonite transport. } \\
\text { Included in calculation. }\end{array}$ \\
\hline
\end{tabular}


Table A10. Cont.

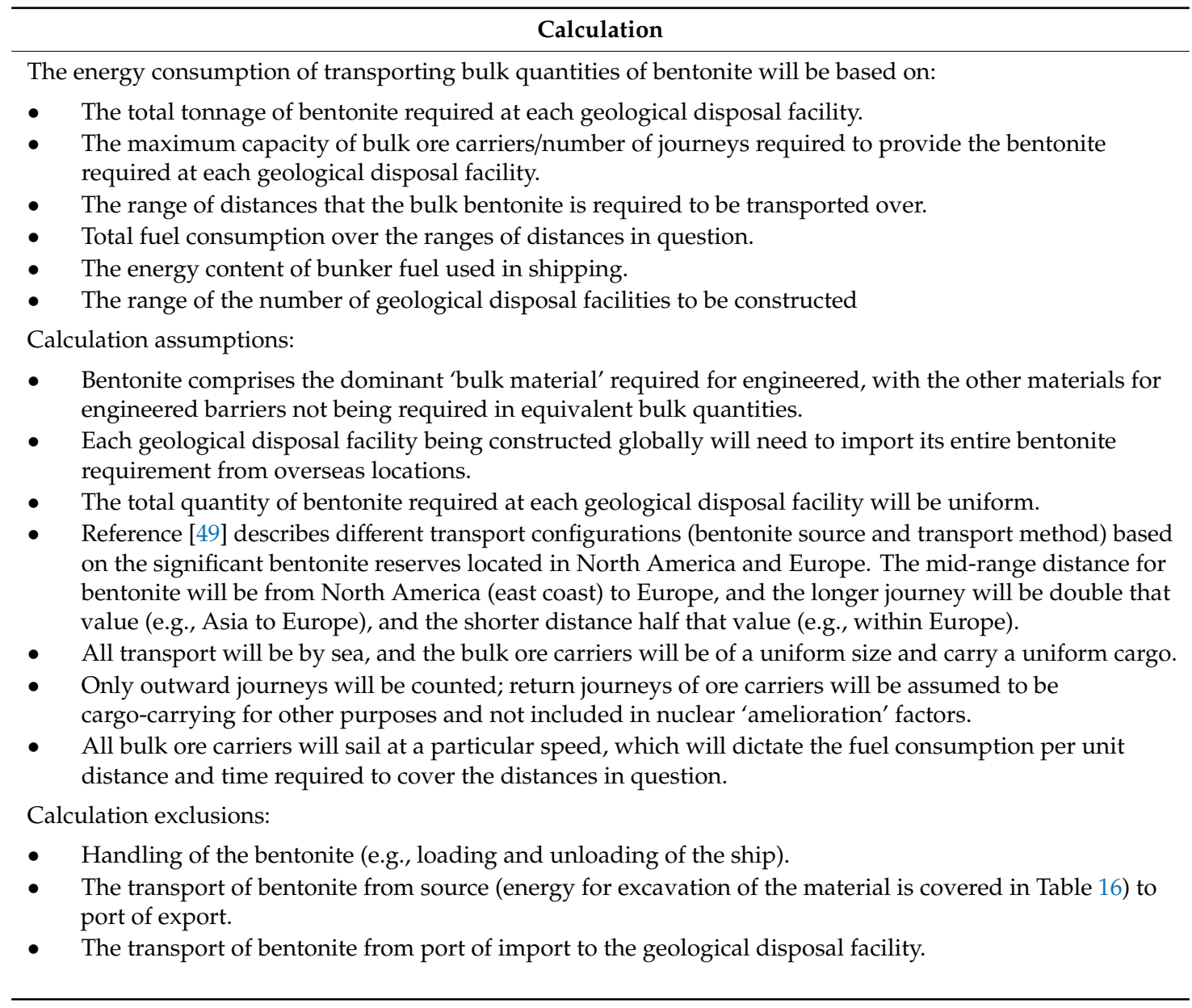

Table A11. Intra-national transport of waste packages to geological disposal facilities.

\begin{tabular}{ll}
\hline \multicolumn{1}{c}{ Discussion } & \multicolumn{1}{c}{ Conclusion } \\
\hline $\begin{array}{l}\text { The transport of different radioactive materials being undertaken } \\
\text { primarily by road, rail and sea, with the majority of intra-nation } \\
\text { movements of spent fuel taking place by rail [86]. The requirements } \\
\text { for the movements of nuclear and radioactive material within } \\
\begin{array}{l}\text { countries varies significantly according to factors such as the fuel } \\
\text { cycle employed, the distribution of power plants and waste } \\
\text { management infrastructure, and the geographical area of the } \\
\text { country. }\end{array}\end{array}$ & $\begin{array}{l}\text { Likely not a major energy investment due to } \\
\text { the inherent efficiency of rail transport and } \\
\text { non-bulk nature of the material } \\
\text { requiring transport. }\end{array}$ \\
& $\begin{array}{l}\text { Quantification will need to account for } \\
\text { variation in the distances transport will be } \\
\text { required for, and the total number of waste } \\
\text { packages, in different countries. } \\
\text { To be quantified as part of future work. }\end{array}$ \\
\hline
\end{tabular}

Table A12. Human capital required to support 'amelioration' factors.

\begin{tabular}{ll}
\hline \multicolumn{1}{c}{ Discussion } & \multicolumn{1}{c}{ Conclusion } \\
\hline $\begin{array}{l}\text { The implementation of very large, long-duration projects such as } \\
\text { geological disposal facilities requires the expenditure of large } \\
\text { amounts of human labour (both intellectual and physical) directly } \\
\text { for planning and management, and also in the extensive supply } \\
\text { chains and support organisations (e.g., government) that are linked } \\
\begin{array}{l}\text { to 'amelioration' projects. In project management human capital } \\
\text { expenditure is usually captured in terms of 'person-hours' or } \\
\text { financial metrics (e.g., for salaries, or costs of support infrastructure } \\
\text { such as laboratories and office buildings). }\end{array}\end{array}$ & $\begin{array}{l}\text { Likely not a major energy investment in } \\
\text { comparison to energy-intensive industrial } \\
\text { processes, but varied forms of human input will } \\
\text { be required at every stage of decommissioning } \\
\text { and geological disposal. } \\
\text { Quantification will require a framework to be } \\
\text { formulated for consideration of human capital } \\
\text { expenditure in biophysical terms. } \\
\text { To be quantified as part of future work. }\end{array}$ \\
\hline
\end{tabular}




\section{References}

1. The World Nuclear Industry Status Report. 2019. Available online: https:/www.worldnuclearreport.org/ IMG/pdf/wnisr2019-v2-hr.pdf (accessed on 15 April 2020).

2. Nuclear Power in the World Today. Available online: https://www.world-nuclear.org/information-library/ current-and-future-generation/nuclear-power-in-the-world-today.aspx (accessed on 17 August 2020).

3. Outline History of Nuclear Energy. Available online: https://www.world-nuclear.org/information-library/ current-and-future-generation/outline-history-of-nuclear-energy.aspx (accessed on 17 August 2020).

4. BP Statistical Review of World Energy 2019, 68th Edition. Available online: https://www.bp.com/content/ $\mathrm{dam} / \mathrm{bp} / \mathrm{business-sites/en/global/corporate/pdfs/energy-economics/statisticas-review/bp-stats-review-}$ 2019-full-report.pdf (accessed on 30 April 2020).

5. BP Energy Outlook, 2019 Edition. Available online: https://www.bp.com/content/dam/bp/businesssites/en/global/corporate/pdfs/energy-economics/energy-outlook/bp-energy-outlook-2019.pdf (accessed on 30 April 2020).

6. Pearce, J.M. Thermodynamic limitations to nuclear energy deployment as a greenhouse gas mitigation technology. Int. J. Nucl. Gov. Econ. Ecol. 2008, 2, 113-130. [CrossRef]

7. Monasterolo, I.; Jones, A.; Tonelli, F.; Natalini, D. A hybrid System Dynamics-Agent Based model to simulate Complex Adaptive Systems: A new methodological framework for sustainability analysis. In Proceedings of the 32nd International Conference of the System Dynamics Society, Delft, The Netherlands, 24 July 2014.

8. IAEA. Climate Change and Nuclear Power. 2018. Available online: https://www.iaea.org/publications/13395/ climate-change-and-nuclear-power-2018 (accessed on 4 May 2020).

9. Capellán-Pérez, I.; de Blas, I.; Nieto, J.; de Caste, C.; Miguel, L.J.; Carpintero, Ó.; Mediaville, M.; Lobejón, L.F.; Ferreras-Alonso, N.; Rodrigo, P.; et al. MEDEAS: A new modeling framework integrating global biophysical and socioeconomic constraints. Energy Environ. Sci. 2020, 13, 986. [CrossRef]

10. Beerten, J.; Laes, E.; Meskens, G.; D'haeseleer, W. Greenhouse gas emissions in the nuclear life cycle: A balanced appraisal. Energy Policy 2009, 37, 5056-5068. [CrossRef]

11. Special Report-Global Warming of $1.5{ }^{\circ} \mathrm{C}$. Available online: https://www.ipcc.ch/sr15 (accessed on 1 September 2020).

12. Hall, C.A.S.; Lambert, J.G.; Balogh, S.B. EROI of different fuels and the implications for society. Energy Policy 2013, 64, 141-152. [CrossRef]

13. Diesendorf, M.; Wiedmann, T. Implications of Trends in Energy Return on Energy Invested (EROI) for Transitioning to Renewable Electricity. Ecol. Econ. 2020, 176, 106726-106733. [CrossRef]

14. Brockway, P.E.; Owen, A.; Brand-Correa, L.I. Estimation of global final-stage energy-return-on-investment for fossil fuels with comparison to renewable energy sources. Nat. Energy 2019, 4, 612-621. [CrossRef]

15. Raugei, M. Net Energy Analysis must not compare apples and oranges. Nat. Energy 2019, 4, 86-88. [CrossRef]

16. Goldin, I.; Mariathasan, M. The Butterfly Defect. How Globalization Creates Systemic Risks, and What to Do about It; Princeton University Press: Princeton, NJ, USA; Oxford, NJ, USA, 2014; pp. 9-33, 100-120.

17. Jarvis, A. Energy Returns and The Long-run Growth of Global Industrial Society. Ecol. Econ. 2018, 146, 722-729. [CrossRef]

18. Sgouridis, S.; Csala, D.; Bardi, U. The sower's way: Quantifying the narrowing net-energy pathways to a global energy transition. Environ. Res. Lett. 2016, 11, 094009. [CrossRef]

19. Love, T.; Isenhour, C. Energy and economy: Recognizing high-energy modernity as a historical period. Econ. Anthropol. 2016, 3, 6-16. [CrossRef]

20. Hall, C.A.S. Will EROI be the Primary Determinant of Our Economic Future? The View of the Natural Scientist versus the Economist. Joule 2017, 1, 635-638. [CrossRef]

21. Carbajales-Dale, M. When is EROI Not EROI? Biophys. Econ. Resour. Qual. 2019, 4, 16. [CrossRef]

22. Lenzen, M. Life cycle energy and greenhouse gas emissions of nuclear energy: A review. Energy Convers. Manag. 2008, 49, 2178-2199. [CrossRef]

23. Weissbach, D.; Ruprecht, G.; Huke, A.; Czerski, K.; Gottlieb, S.; Hussein, A. Energy intensities, EROIs (energy returned on invested), and energy payback times of electricity generating power plants. Energy 2013, 52, 210-221. [CrossRef] 
24. Raugei, M.; Carbajales-Dale, M.; Barnhart, C.J.; Fthenakis, V. Rebuttal: “Comments on ‘Energy intensities, EROIs (energy returned on invested), and energy payback times of electricity generating power plants' Making clear of quite some confusion". Energy 2015, 82, 1088-1091. [CrossRef]

25. Hall, C.A.S.; Balogh, S.; Murphy, D.J.R. What is the Minimum EROI that a Sustainable Society Must Have? Energies 2009, 2, 25-47. [CrossRef]

26. Murphy, D.J.; Hall, C.A.S.; Dale, M.; Cleveland, C. Order from Chaos: A Preliminary Protocol for Determining the EROI of Fuels. Sustainability 2011, 3, 1888-1907. [CrossRef]

27. Tainter, J.A. The Collapse of Complex Societies; Cambridge University Press: Cambridge, UK, 1988; pp. 22-37, 93-108.

28. Steffen, W.; Broadgate, W.; Deutsch, L.; Gaffney, O.; Ludwig, C. The trajectory of the Anthropocene: The Great Acceleration. Anthr. Rev. 2015, 2, 81-98. [CrossRef]

29. Friedrichs, J. Global energy crunch: How different parts of the world would react to a peak oil scenario. Energy Policy 2010, 38, 4562-4569. [CrossRef]

30. Bardi, U. The Seneca Effect. Why Growth Is Slow but Collapse Is Rapid; Springer International Publishing: Cham, Switzerland, 2017; pp. 1-5.

31. Saudi Aramco Becomes Most Valuable Listed Company in History. Available online: https://www.theguardian.com/business/2019/dec/11/saudi-aramco-shares-soar-as-it-becomes-worldlargest-listed-company (accessed on 17 August 2020).

32. Energy Return on Investment. Available online: https://www.world-nuclear.org/information-library/energyand-the-environment/energy-return-on-invesinves.aspx (accessed on 15 April 2020).

33. Raugei, M. Comments on "Energy intensities, EROIs (energy returned on invested), and energy payback times of electricity generating power plants"-Making clear of quite some confusion. Energy 2013, 59, 781. [CrossRef]

34. van Leeuwen, J.W.S. Climate Change and Nuclear Power-An Analysis of Nuclear Greenhouse Gas Emissions; World Information Service on Energy: Amsterdam, The Netherlands, 2017; pp. 4-63.

35. Gupta, A.K.; Hall, C.A.S. A Review of the Past and Current State of EROI Data. Sustainability 2011, 3, 1796-1809. [CrossRef]

36. Sovacool, B.K. Valuing the greenhouse gas emissions from nuclear power: A critical survey. Energy Policy 2008, 36, 2950-2963. [CrossRef]

37. Lewitz, J.-C.; Huke, A.; Ruprecht, G.; Weissbach, D.; Gottlieb, S.; Hussein, A.; Czerski, K. The Dual Fluid Reactor-An Innovative Fast Nuclear-Reactor Concept with High Efficiency and Total Burnup. ATW 2020, 65, 145-154.

38. Lambert, J.G.; Hall, C.A.S.; Balogh, S.; Gupta, A.; Arnold, M. Energy, EROI and quality of life. Energy Policy 2013, 64, 153-167. [CrossRef]

39. Building Careers in Nuclear Decommissioning. Available online: https://www.neimagazine.com/features/ featurebuilding-careers-in-nuclear-decommissioning-7865269/ (accessed on 15 April 2020).

40. Annual Report and Accounts 2018/19. Available online: https://assets.publishing.service.gov.uk/government/ uploads/system/uploads/attachment_data/file/814718/NDA_Annual_Report_and_Accounts_2018_to_ 2019v2.pdf (accessed on 9 April 2020).

41. Managing Our Radioactive Waste Safely. CoRWM's Recommendations to Government. Available online: https://assets.publishing.service.gov.uk/government/uploads/system/uploads/attachment_data/file/ 294112/700_-_CoRWM_July_2006_Recommendations_to_Government_pdf.pdf (accessed on 9 April 2020).

42. Annual Report and Accounts 2018-19. Available online: https://assets.publishing.service.gov.uk/government/ uploads/system/uploads/attachment_data/file/851028/RWM_Annual_Report_and_Accounts_2018_19.pdf (accessed on 9 April 2020).

43. National Policy Statement for Geological Disposal Infrastructure. Available online: https: //assets.publishing.service.gov.uk/government/uploads/system/uploads/attachment_data/file/676406/ Final_NPS_Consultation_Document.pdf (accessed on 10 April 2020).

44. ANDRA-2016 Financial Report. Available online: https://international.andra.fr/sites/international/files/ 2019-03/Andra-Rapport_financier_2016_EN.pdf (accessed on 9 April 2020).

45. NAGRA-Annual Report. 2018. Available online: https://www.nagra.ch/en/downloadcentre.htm (accessed on 15 April 2020). 
46. Geological Disposal-The 2013 Derived Inventory. Available online: https://rwm.nda.gov.uk/publication/ 2013-derived-inventory/ (accessed on 4 May 2020).

47. Delay, J.; Bossart, P.; Ling, L.X.; Blechschmidt, I.; Ohlsson, M.; Vinsot, A.; Nussbaum, C.; Maes, C. Three decades of underground research laboratories: What have we learned? Geol. Soc. London Spec. Publ. 2014, 400. [CrossRef]

48. Plan. 2019. Available online: https://www.skb.se/publikation/2493480/Plan+2019.pdf (accessed on 15 April 2020).

49. Project JADE-Comparison of Repository Systems, Executive Summary of Results, Technical Report TR-01-17. Available online: https://skb.se/upload/publications/pdf/TR-01-17.pdf (accessed on 15 April 2020).

50. Annual Report. 2018. Available online: http://www.posiva.fi/en/databank/publications/annual_reports/ annual_report_2018.2271.xhtml\#.XpdNLk1YZjo (accessed on 15 April 2020).

51. Annual Report. 2018. Available online: https://www.nwmo.ca/en/More-information/News-and-Activities/ 2019/03/22/19/16/NWMO-Submits-2012-Annual-Report (accessed on 15 April 2020).

52. Chernobyl New Safe Confinement: A One-of-a-Kind Project. Available online: https: //www.vinci.com/vinci/actualites.nsf/8B8A50CC6F1891E8C1258079005011BA/\$File/VINCI_RV_DosDoss_ de_presse_Tchernobyl_GB.pdf (accessed on 15 April 2020).

53. Safely Disposed of More than 170,000 Waste Containers. Available online: https://www.wipp.energy.gov (accessed on 31 August 2020).

54. Deák, F.; Kovács, L.; Vásárhelyi, B. Modeling the Excavation Damaged Zone in the Bátaapáti radioactive waste repository. Rock Mech. Resour. Energy Environ. 2013, 603-608. [CrossRef]

55. Hungarian Repository Receives First Waste. Available online: https://world-nuclear-news.org/Articles/ Hungarian-repository-receives-first-waste (accessed on 31 August 2020).

56. Power Reactor Information System-Nuclear Share of Electricity Generation in 2018. Available online: https: //pris.iaea.org/PRIS/WorldStatistics/NuclearShareofElectricityGeneration.aspx (accessed on 4 May 2020).

57. Zimmerman, J.; Pelosi, M.; Williamson, C.A.; Ivantysynova, M. Energy Consumption of an LS Excavator Hydraulic System. In Proceedings of the ASME International Mechanical Engineering Congress and Exposition, Seattle, WA, USA, 11-15 November 2007.

58. Geddes, S. Estimating for Building and Civil. Engineering Works, 9th ed.; Spon Press: London, UK; New York, NY, USA, 1996.

59. The Sellafield Contaminated Land and Groundwater Management Project: Characterisation of A Complex Nuclear Facility. Available online: https://inis.iaea.org/collection/NCLCollectionStore/_Public/45/073/ 45073599.pdf?r=1\&r=1 (accessed on 10 May 2020).

60. Land Remediation of the Liquid Effluent Treatment Plant (LETP). Available online: https://www.nuvia.com/ projects/land-remediation-of-the-liquid-effluent-treatment-plant-letp/ (accessed on 10 May 2020).

61. Projects: Hunterston Land Remediation. Available online: http://www.nuvia.co.uk/projects-hunterston.asp (accessed on 10 May 2020).

62. Dorf, R. Engineering Handbook; CRC Press: New York, NY, USA, 1996.

63. Worrell, E.; Galitsky, C.; Kermeli, K. Energy Efficiency Improvement and Cost Saving Opportunities for Cement Making An ENERGY STAR®Guide for Energy and Plant Managers. LBNL 54036 Revis. USA 2008. [CrossRef]

64. Vitrified Packages (HLW). Available online: https://www.radioactivity.eu.com/site/pages/Vitrified_HA_ Waste.htm (accessed on 10 May 2020).

65. Szalatkiewicz, J. Construction Materials from Vitrified Lignite Fly Ash in Plasmatron Plasma Reactor. Materials 2019, 12, 905. [CrossRef]

66. Geological Disposal—Generic Disposal Facility Design. Available online: https://assets.publishing.service. gov.uk/government/uploads/system/uploads/attachment_data/file/635116/NDA_Report_no_DSSC-41201_-_Geological_Disposal_-_Generic_Disposal_Facility_Designs.pdf (accessed on 4 May 2020).

67. Onkalo Nuclear Waste Disposal Facility. Available online: https:/www.nsenergybusiness.com/projects/ onkalo-nuclear-waste-disposal-facility/ (accessed on 4 May 2020).

68. Grishenko, V. Energy Efficiency of Tunnel Boring Machines. Master's Thesis, Royal Institute of Technology (KTH), Stockholm, Sweden, 2014.

69. Rankin, R. Energy Use in Metal Production. In Proceedings of the High Temperature Processing Symposium, Melbourne, Australia, 6-7 February 2012. 
70. Developing Strategies for Acquisition and Control of Bentonite for A High Level Radioactive Waste Repository, Technical Report TR-16-14. Available online: https://www.skb.se/publikation/2489029/TR-16-14.pdf (accessed on 18 April 2020).

71. Bentonite EC No. 215-108-5, CAS No. 1302-78-9. Available online: https://bentonite.it/what-is-bentonite.php (accessed on 12 May 2020).

72. Zonailo, G.W. Transportation by rail and sea in the coal industry. In The Coal Handbook: Towards Cleaner Production; Woodhead Publishing: Boston, UK, 2013; pp. 705-730.

73. Fuel Consumption by Containership Size and Speed. Available online: httpsjarv://transportgeography.org/ ?page_id=5955 (accessed on 11 May 2020).

74. Energy Content of Some Combustibles (in MJ/kg). Available online: https://transportgeography.org/?page_ $\mathrm{id}=5837$ (accessed on 11 May 2020).

75. Key World Energy Statistics. 2019. Available online: https://webstore.iea.org/key-world-energy-statistics2019 (accessed on 12 May 2020).

76. Abbott, D. Limits to growth: Can nuclear power supply the world's needs? Bull. At. Sci. 2012, 68, $23-32$. [CrossRef]

77. Capellán-Pérez, I.; de Castro, C.; Miguel González, L.J. Dynamic Energy Return on Energy Investment (EROI) and material requirements in scenarios of global transition to renewable energies. Energy Strategy Rev. 2019, 26. [CrossRef]

78. Zittel, W.; Schindler, J. Uranium Resources and Nuclear Energy. Energy Watch Group, EWG Paper 1/06. December 2006. Available online: http://www.lbst.de/ressources/docs2007/EWG-paper_1-06_UraniumResources-Nuclear-Energy_03DEC2006.pdf (accessed on 12 October 2020).

79. Smith, D.R. On-load refuelling for power reactors. In General Studies of Nuclear Reactors; Geary, N., Ed.; Sterling Publications: London, UK, 1987; pp. 170-173.

80. Accelerating Ractor Decommissioning. Available online: https://www.neimagazine.com/features/ featureaccelerating-reactor-decommissioning-7895276 (accessed on 29 April 2020).

81. Defra Research Project Final Report. Available online: https://www.sciencesearch.defra.gov.uk/Document. aspx?Document=SP1001_9957_FRP.pdf (accessed on 3 May 2020).

82. Vitrified High-Level Waste at Sellafield (Pre-Conceptual Stage)—Summary of Assessment Report. Available online: https://rwm.nda.gov.uk/publication/executive-summary-letter-of-compliance-assessment-reportvitrified-high-level-waste-april-2009 (accessed on 3 May 2020).

83. Choice of Rock Excavation Methods for The Swedish Deep Repository for Spent Nuclear Fuel, R-04-62. Available online: https://www.skb.se/publication/22542/R-04-62.pdf (accessed on 6 May 2020).

84. Geological Disposal-Generic Operational Safety Case-Main Report. Available online: https://rwm.nda.gov. uk/publication/geological-disposal-generic-operational-safety-case-main-report (accessed on 6 May 2020).

85. Lyengar, M.; Schmidt, R. Energy Consumption of Information Technology Data Centres. Electron. Cool. 2010, $16,30-31$.

86. Transport of Radioactive Materials. Available online: https:/www.world-nuclear.org/informationlibrary/nuclear-fuel-cycle/transport-of-nuclear-materials/tratransp-of-radioactive-materials.aspx (accessed on 6 May 2020).

(C) 2020 by the authors. Licensee MDPI, Basel, Switzerland. This article is an open access article distributed under the terms and conditions of the Creative Commons Attribution (CC BY) license (http://creativecommons.org/licenses/by/4.0/). 